\title{
Comerciantes y redes mercantiles del siglo XVII en la frontera sur del Virreinato del Perú
}

\author{
Margarita Gascón \\ INCIHUSA-CRICYT Centro Regional de Investigaciones \\ Mendoza, Argentina
}

La revuelta de los araucanos de 1598-1599 implicó, como es bien conocido, un cambio profundo en la región sur de Chile y en su capital, Santiago. La influencia de Arauco en la evolución del Chile colonial ha sido analizada desde numerosas perspectivas historiográficas. Menos conocido es, sin embargo, el impacto que tuvo esta zona de frontera con Arauco en las colonias trasandinas, en el actual territorio argentino, durante el siglo XVII. En efecto, el establecimiento de un ejército profesional en esta periferia austral del imperio español en Indias impulsó cambios en Mendoza, Córdoba y finalmente Buenos Aires que se relacionan fundamentalmente (aunque no exclusivamente) con el abastecimiento de las tropas. Este trabajo analiza las redes mercantiles dentro de las que operaron los principales comerciantes del siglo XVII de Santiago, Mendoza, Córdoba y Buenos Aires en relación con el ejército real establecido en la frontera del sur de Chile. Se describe, por una parte, cómo estos mercaderes operaron en las cuatro colonias de la periferia austral del Virreinato del Perú y, por otra parte, se verifica que un importante volumen de sus negocios se relaciona con el flujo de recursos materiales y humanos desde Cuyo, Tucumán, Río de la Plata e incluso Paraguay hacia los mercados chilenos.

A partir de principios del siglo XVII, una parte importante de las redes mercantiles de la periferia sur del Virreinato del Perú se relaciona con el establecimiento de un ejército profesional en Chile. A fines de 1598 y principios de 1599 los araucanos iniciaron una masiva rebelión contra los españoles que fueron derrotados en Curalaba. Esto obligó al abandono de los asentamientos hispanos en Arauco y a que la Corona implementase medidas inusuales para la defensa de estos territorios. ${ }^{1}$ El Consejo de Indias

1 Las consecuencias de esta medida han sido especificadas en mi artículo, "La articulación de Buenos Aires a la frontera sur del Imperio español, 1640-1740", Anuario IEHS, 13, Universidad Nacional del Centro de la Provincia de Buenos Aires, Tandil, 1998, págs. 193-214. Para una descripción detallada, ver mi disertación doctoral "The Southern Frontier of the Spanish Empire, 1598-1740", defendida en la University of Ottawa, Canadá. Mi mayor gratitud es hacia el doctor Jacques Barbier por su apoyo y dedicación durante mis estudios de postgrado. La School of Graduate Studies and Research de esa universidad y el Gobierno de Ontario contribuyeron financieramente. Dos becas de investigación postdoctoral en Estados Unidos me permitieron la consulta de valiosas colecciones especiales: la beca María Elena Cassiet en la John Carter Brown Library, Providence, Rhode Island, y la beca Newberry Library Short-term Fellowship, en la Newberry Library de Chicago, Illinois. 
estimó conveniente el aviamiento y transporte de 1.500 hombres y el 19 de junio de 1600 insistió en que se exigiera al Consejo de Hacienda conseguir los 100.000 ducados necesarios para enviar 1.200 hombres al ejército chileno. ${ }^{2}$ Finalmente, las tropas salieron de Lisboa hacia el Río de la Plata con la esperanza de pacificar la frontera con Arauco en poco tiempo. ${ }^{3}$ Pero nunca ocurrió, de modo que más allá del efecto en la esfera militar que tuvo el establecimiento de un ejército profesional en los confines de Indias, el económico fue el impacto más duradero ya que las comunidades cercanas fueron las encargadas de su abastecimiento, creciendo así el comercio regional e interregional, estimulado por la llegada (irregular) del situado que incluía prendas de vestir y elementos para la guerra. A principios del siglo XVII algunas fuentes señalan las dificultades para mantener la disciplina porque el situado llegaba irregularmente. Santiago de Tesillo, por ejemplo aseguró que "los soldados andaban descalzos y sin ropas porque se las jugaban" como forma de conseguir recursos debido a la falta de pagos por sus servicios. Y en 1656 el gobernador Pedro Porter Casanate volvió a confirmar que en el presidio de Valdivia los soldados se iban con los indios para poder comer, ya que no se recibía el situado regularmente. Tales dificultades no impidieron, sin embargo, que el situado fuese una base del crédito y del comercio para esta zona de Indias, según los análisis de Te Paske y Klein. ${ }^{4}$

Las redes mercantiles que se analizan en este trabajo se vinculan con el abastecimiento de ese ejército en la frontera con Arauco. El estudio de las redes tanto familiares como mercantiles es ya un tema tradicional en la historiografía colonial hispanoamericana, y en este análisis, tales redes explican el efectivo flujo de recursos por extensas y desoladas rutas de la

2 "Informe del Consejo de Indias sobre la urgencia de enviar socorros a Chile, 19 de junio de 1600", en Medina, José Toribio, ed.: Colección de Documentos para la Historia de Chile. Santiago, 1961, tomo V (1599-1602), pág. 355.

3 Según el gobernador Francisco Quiñones (1599-1600), unos mil soldados bien armados, que trajeran sus cabalgaduras y pagados a razón de 12 pesos corrientes de a 9 reales permitirían concluir la guerra en tres años; en "Relación del Estado del Reino", en Medina, ed.: Colección de Documentos..., tomo V, pág. 276.

4 Santiago de Tesillo: Epítome chileno. Ideas contra la paz. Lima, 1648, foja 40, en The John Carter Brown Library: en adelante, JCBL. Porter Casanate, Pedro: "Relación de los Felizes Successos Que Ha Dado Dios A las Reales Armas del Rey, Nuestro Señor en el Reino de Chile, desde el primero dia de enero de 1656", Madrid, 1656, foja 11, JCBL. Para detalles del situado en Chile, ver Te Paske, John: "The Costs of Empire: Spending Patterns and Priorities in Colonial Peru, 1581-1820", Colonial Latin American Historical Review (en adelante, CLAHR) 1:2, winter, 1993, págs.1-34; y The Royal Treasuries of the Spanish Empire in America. Durkham, 1982; y Slicher van Bath, B.H: Real Hacienda y Economía en Hispanoamerica, 1541-1820. Amsterdam, 1989. Algunos aportes macro-económicos recientes provienen del análisis de Klein, Herbert: The American Finances of the Spanish Empire: Royal Income and Expenditures in Colonial Mexico, Peru and Bolivia, 1680-1809. Albuquerque, 1998. 
periferia austral del Virreinato del Perú. ${ }^{5}$ Se especifica la situación en Arauco para contextualizar las redes mercantiles que surgieron, se mantuvieron y modificaron a lo largo del siglo XVII siguiendo la evolución de esta frontera. ${ }^{6}$ Finalmente, esta investigación aporta tanto a los estudios de

5 Las redes basadas en el parentesco han permitido varias interpretaciones de la historia colonial hispanoamericana. Los autores reconstruyen las redes en cada colonia (intra-redes) y redes con otras colonias (inter-redes); ver, por ejemplo, Balmori, Diana, y Oppenheimer, Robert: "Family Clusters: Generational Nucleation in the Nineteenth Century Argentina and Chile", Comparative Studies in Society and History, 2:2, 1979, págs.231-261; y Balmori, D.; Voss, C., y Wortman, M.: Las alianzas de familia y la formación del país en América Latina. México, 1992; Blank, Stephanie: "Patrons, Clients and Kin in Seventeenth-century Caracas: A Methodological Essay in Colonial Spanish America Social History", Hispanic America Historical Review (en adelante, HAHR) 54:2, mayo de 1974, págs. 260-284; y "Patrons, Brokers and Clientes in the Families of the Elite in Colonial Caracas, 1595-1627”, The Americas, 36:1, julio de 1979, págs. 90-116; Booker, Jackie: “The Veracruz Merchant Community in Late Bourbon Mexico: A Preliminary Portrait, 1770-1810", The Americas, 45:2, octubre de 1988, págs. 187-201; Florescano, Enrique, comp.: Orígenes y Desarrollo de las burguesías de América Latina (1750-1955). México, 1985; Flusche, Della: Two Families in Colonial Chile. Leviston, 1990; y "Doña Isabel Osorio de Cáceres: Chilean Matriarch", CLAHR, 3:1, 1994, págs. 3971; Gabay, Rafael, y Pieter, Auke: "Wealth and Spanish Investment. The Pizarro Family during the Sixteenth Century", HAHR, 67:4, noviembre de 1987, págs. 657-697; Gascón, Margarita: "The Military of Santo Domingo, 1720-1764", HAHR, 73:3, agosto de 1993, págs. 431-452; Gelman, Jorge: “Cabildo y elite local: el caso de Buenos Aires en el siglo XVII", HISLA, VI, 1985, págs. 3-19; Gonzalbo, Pilar, ed.: Familias Novohispanas. Siglos XVI al XIX. México, 1991; Haberman, Louisa: "Merchants in the Seventeenth-century Mexico City. A Preliminary Portrait", HAHR, 57:3, agosto de 1977, págs. 479504; y Mexico's Merchant Elite, 1590-1660. Silver, State and Society. Durham, 1991; Mecle, Elina: La Ciudad Puerto: la expansión económica de las primeras familias. Buenos Aires, 1989; Metcalf, Alida: Family and Frontier in Colonial Brazil: Santana de Paranaiba, 1580-1822. Berkeley, 1992; Moutoukías, Zacarías: "Power, Corruption and Commerce. The Making of the Local Administrative Structure in Seventeenth-century Buenos Aires", HAHR, 68:4, diciembre de 1988, págs. 213-246; Paz, Gustavo: "Familia, Linaje y red de parientes. La Elite de Jujuy en el siglo XVIII", Andes, 8, Salta, 1997, págs. 145-174; Presta, Ana María: "Encomienda, famila y redes en Charcas Colonial. Los Almendros, 1540-1600", Memoria Americana, 5, Buenos Aires, 1996, págs. 9-32; Ramirez, Susan: "Instability at the top: A Social History of the Landed Elite in Colonial Peru", Colonial Latin American Historical Review, 3:3, summer, 1994, págs. 327-346; Ramos, Donald: "Marriage and Family in Colonial Villa Rica", HAHR, 55:2, mayo de 1975, págs. 200-226; Socolow, Susan: The Merchants of Buenos Aires, 1778-1810. Family and Commerce. Cambridge, 1972; y "Economic Activities of the Porteño Merchants: The Viceregal Period", HAHR, 55:1, febrero de 1975, págs. 1-25; Twinam, Ann: "Enterprise and Elites in Seventeenth-century Medellín”, HAHR, 59:3, agosto de 1979, págs. 444-476; Kicsa, John: Colonial Entrepreneurs. Families and Business in Bourbon Mexico City. Albuquerque, 1983; y "The Great Families of Mexico. Elite Maintenance and Business Practices in Late Colonial Mexico City", HAHR, 62:3, agosto de 1982, págs. 429-458.

6 La bibliografía sobre la frontera con Arauco es abundante y solamente cito algunas obras recientes. Para un balance, ver Jones, Kristine: "Comparative Ethnohistory and the Southern Cone", Latin American Research Review, 29:1, 1994, págs. 107-115; Blancpain, Jean Pierre: Les Araucans et la frontière dans l'histoire du Chili des origins au XIXème siécle. Frankfurt am Main, 1990; Dillehay, Tom: Araucania: presente y pasado. Santiago, 1990; Pinto, Jorge, et al.: Misioneros en la Araucania, 16001900. Temuco, 1988; Zapater, Horacio: "Huincas y Mapuches (1550-1662)", Historia, 30, 1997, págs. 441-504; Boccara, Guillaume: "Notas acerca de los dispositivos de poder en la sociedad colonial fronteriza, la resistencia y la transculturación de los reche-mapuches del Centro-sur de Chile (XVI-XVIII)", 
frontera como a los referidos al siglo XVII que dejan de lado la tradicional perspectiva historiográfica concentrada en la circulación de bienes y servicios en el eje Buenos Aires-Córdoba-Potosí. ${ }^{?}$

\section{Presión sobre los recursos por la instalación del ejército real en Arauco}

La presencia de un ejército de unas aproximadamente 2.000 plazas en promedio para el siglo XVII afectó a los recursos humanos y materiales disponibles en Chile, al crear un mercado consumidor alimentado por el situado que irregularmente llegaba desde Lima. Según un estudio, Chile consumía dos tercios de todos los pagos efectuados por el situado de la Caja de Lima durante el período colonial. ${ }^{8}$ Podemos imaginar las consecuencias que esto tuvo en una economía periférica con el siguiente dato: según su propio informe, el virrey marqués de Guadalcázar (1622-1629) envió 3.215.073 pesos a Chile durante su mandato en concepto de once situados. ${ }^{9}$

Destinado a solucionar el conflicto con los araucanos por medio de su sometimiento y control por parte del ejército profesional, el situado sin embargo contribuyó a mantener la frontera estabilizada, pero nunca pacificada completamente como para que fuese posible suprimir, o al menos reducir, los gastos de guerra. Las autoridades reales muy pronto comprendieron que las ventajas económicas de recibir un situado eran un obstáculo

Revista de Indias, LVI:208, 1996, págs. 659-695; Ruiz-Esquide, Andrea: Los indios amigos en la frontera araucana. Santiago, 1993; León Solís, Leonardo: "Maloqueros, tráfico ganadero y violencia en las fronteras de Buenos Aires y Chile, 1700-1800", Jahburch fur Geschichte von Staat, Wirtschaft, und Gesellschaft Lateinamerikas, 26, 1989, págs. 37-83; Villalobos, Sergio, y Pinto, Jorge: Araucania. Temas de historia fronteriza. Temuco, 1985.

7 Como ejemplos de esta perspectiva se encuentran los estudios de Garavaglia, Juan Carlos: Mercado interno y economía colonial. México, 1983; Sempat Assadourian, Carlos: El tráfico de esclavos en Córdoba, 1586-1610. Córdoba, 1965; y "Potosí y el crecimiento en Córdoba en los siglos XVI y XVII", Universidad Nacional de Córdoba, ed.: Homenaje al Dr. Ceferino Garzón Maceda. Córdoba, 1973, págs. 169-205; Santamaría, Daniel: "Intercambios comerciales internos en el Alto Perú colonial tardío", Revista Complutense de Historia de América, 22, 1996, págs. 239-274; Tandeter, Enrique: Coercion and Market: Silver Mining in Colonial Potosi, 1692-1826. Albuquerque, 1993; Matas de López, Sara: "Articulación regional y mercado interno. Salta en la segunda mitad del siglo XVIII", Cuadernos de Historia Regional, 14, Universidad Nacional de Luján, Buenos Aires, 1989, págs. 42-61; y Palomeque, Silvia: "Intercambios mercantiles y participación indígena en la Puna de Jujuy a fines del período colonial”, Andes, 6, Universidad Nacional de Salta, 1994, págs. 13-48.

8 Te Paske: "The Costs of Empire...", pág. 17.

9 Newberry Library (en adelante, NL), "Relación del estado en que el Marqués de Guadalcázar deja el gobierno del Perú al señor Virrey Conde de Chichón”, en Beltrán, Ricardo, y Razpide, ed.: Colección de las Memorias o Relaciones que escribieron los Virreyes del Peru acerca del estado en que dejaban las cosas generales del Reino. Madrid, 1921, pág. 109. 
para la pacificación de Arauco. El virrey del Perú, príncipe de Esquilache (1615-1621), advirtió que se despachaban 212.000 ducados cada año para 2.000 infantes y soldados "parte va en ropa y otras cosas necesarias". Pero, subrayaba, había alrededor de 1.500 soldados, insinuando así que alguien se quedaba con la diferencia. "Me dicen que es porque se pagan deudas atrasadas, pero yo no les creo", concluyó el virrey. ${ }^{10}$ En otra oportunidad advirtió que siempre habría oposición a la guerra defensiva si esto implicaba una reducción en el situado: “(...) y estoy cierto que han de representar a V. E. grandes miedos y peligros nacidos de esta reformación, y tengo por cierto que proceden más del sentimiento de que vaya este dinero menos, que de tener subsistencia ni fundamento cuanto dijeren". ${ }^{11}$ Cuando el gobernador Laso de la Vega (1629-1639) pidió duplicar el situado y traer 2.000 hombres de España por Buenos Aires, el virrey informó que aun con 4.000 hombres y el doble de situado no había seguridad de acabar la guerra en cinco años, como se prometía. ${ }^{12}$ Otros denunciaron esta situación, como el padre Luis de Valdivia, para quien la guerra defensiva en Arauco nunca prosperaría porque significaba estrangular el beneficio del situado. Valdivia informó que 2.600 soldados se habrían beneficiado de esta guerra entre 1606 y 1609 y que en 18 años el situado había subido de 30 ó 40.000 a 212.000: “(...) siendo el principal ingreso económico para una región que se encontraba despoblada y arruinada por la guerra". ${ }^{13}$

Además de los beneficios posibles que dejaría el irregular situado en la economía local, la presencia del ejército real en Arauco benefició a la élite de Santiago en otras tres formas: 1) con la exención de los deberes militares asociados al beneficio de tener una encomienda; 2) con la creación de un mercado consumidor alternativo al peruano; y 3) con la ampliación de las redes comerciales con las colonias de la vertiente oriental de los Andes. Antes de desarrollar los puntos 2 y 3 que constituyen el tema específico de este trabajo, se advierte que en el primer caso los encomenderos quedaron relevados de las obligaciones militares, pero los miembros de la élite de Santiago no perdieron por ello el acceso a la mano de obra indígena. Al

10 NL, "Billete que escribió el Príncipe de Esquilache al Marqués de Montesclaros, pidiéndole que por escrito le diese relación del estado en que dejaba el reino del Perú: y lo que él le respondió", en Beltrán y Razpide, ed.: Colección de las Memorias..., pág. 14.

11 NL, "Relación del Príncipe de Esquilache al señor Marqués de Guadalcazar sobre el estado en que deja las provincias del Perú”, Beltrán y Razpide, ed.: Colección de las Memorias..., pág. 261.

12 Tesillo: Epitome chileno..., foja 20.

13 JCBL, Luis de Valdivia: "Señor, El Padre Luis de Valdivia de la Compañía de Iesus, Digo que siendo VM informado de la importancia grande de cortar la guerra de Chile, que ha durado 58 años, con tantos daños, y sin efecto de consideración...” Madrid[?], 1610[?], Boston, 1928. 
contrario, la situación de frontera militar permitió seguir capturando indios de guerra y esclavizarlos — primera y principal causa para muchos observadores del estado de rebeldía de los nativos-, o pedir encomiendas como retribución por servicios militares. Tan tarde como 1669, Juan Alfonso Velázquez de Covarrubias recibió las encomiendas de Guanacache y Terlumba en Cuyo, confirmadas por el Rey en 1674. El motivo para recibir una encomienda de huarpes fue que había servido en Arauco. El ejemplo puede ser extremo e inusual por lo tardío y porque a partir de 1641, con la política de los parlamentos, los enfrentamientos con araucanos rebeldes habían disminuido, de modo que recibir una encomienda por servicios militares en Arauco hubiese sido más adecuado para un soldado del siglo XVI antes que para uno del último tercio del siglo XVII.

Con respecto a los puntos 2 y 3 , el aprovisionamiento de las tropas afectó la distribución y el consumo de los recursos materiales del Valle Central. Desde la revuelta araucana de 1598-1599, Santiago era la única colonia de la región con cierta capacidad económica y demográfica como para atender a las necesidades materiales del ejército. En efecto, los asentamientos españoles al sur de Santiago no podían hacerse cargo de las demandas del ejército. Concepción se empobreció y sufrió los terremotos de 1657 y 1687; Valdivia fue abandonada hasta que en 1645 se la fortificó tras el ataque holandés, y tanto Imperial como Villa Rica se despoblaron. ${ }^{14}$ Debido a que el norte de Chile es un desierto extremo, y a que el sur se había perdido después de la insurrección araucana, los colonos de Santiago se vieron forzados a explotar intensamente los recursos disponibles en la estrecha franja fértil del Valle Central. ${ }^{15}$

Con la instalación del ejército se agravó la disponibilidad de recursos tales como ganado porque, según las fuentes, el ejército requería un mínimo de 5.000 cabezas de vacuno anualmente, así que era imprescindible importarlas desde las provincias trasandinas, en el actual territorio argentino. En el

14 Sobre la evolución de los asentamientos en Arauco durante el siglo XVII, ver Campos Harriet, Fernando: Historia de Concepción, 1550-1970. Santiago, 1979; Academia Nacional de la Historia, ed.: Real Audiencia de Concepción. Santiago, 1992; y Espejo, Juan: Nobiliario de la Capitanía General de Chile. Santiago, 1967.

15 En los alrededores de Santiago, la entrega de tierras puede considerarse terminada a principios del siglo XVII, ver Silva Vargas, Fernando: Tierras y pueblos de indios en el Reino de Chile. Esquema histórico-jurídico. Santiago, 1962, págs. 68-70; Góngora, Mario: Encomenderos y Estancieros. Estudios acerca de la constitución social aristocrática de Chile después de la conquista, 1580-1660. Santiago, 1970; y "Urban Social Stratification in Colonial Chile", HAHR, 55:3, agosto de 1975, págs. 421-449. Como estudios complementarios, ver Bauer, Arnold: Chilean Rural Society from Spanish Conquest to 1930. Cambridge, 1975. 
contexto de la economía peruana para el siglo XVII, estos datos confirman las conclusiones de numerosos estudios sobre la diversificación de las actividades productivas, que se fueron ampliando a partir de la minería y del comercio trasatlántico del siglo XVI. En Chile, a principios de la conquista, las minas de oro desde La Serena en el norte hasta Osorno y Valdivia en el sur ocupaban el primer lugar en la economía chilena. Pero a principios del XVII, sin embargo, ante el creciente agotamiento de los depósitos de fácil aprovechamiento, se hizo todavía más evidente la necesidad de iniciar una explotación sistemática de otros recursos, especialmente del ganado ya que permitiría la exportación de sebo y cueros a los mercados del Perú. ${ }^{16} \mathrm{Hacia}$ mediados de siglo XVII el ejército consumía 8.000 vacas anualmente por lo cual se compraron 30.000 vacas que se arrearon desde las pampas argentinas para las estancias reales en Catentota. ${ }^{17}$ En 1661 el gobernador Pedro Porter Casanate (1656-1662) aseguró que había recibido 14.000 cabezas durante los tres años anteriores y el gobernador Angel de Paredo (1662-1664) aseguró que necesitaba 8.000 cabezas de ganado por año como mínimo. ${ }^{18}$

El ejército profesional había llegado a Chile a mediados de la primera década del siglo XVII. Lo conducía Antonio de Mosquera y se lo conoce como la expedición de "Los Mil Hombres", a pesar de que su número no superó los $600 .{ }^{19}$ Mosquera transitó la ruta que en 1583 había utilizado

16 Sobre la evolución de la economía del Perú desde el siglo XVI hasta finales del XVII, ver Andrien, Kenneth: Crisis and Decline: The Viceroyalty of Peru in the Seventeenth Century. Albuquerque, 1985; Bakewell, Peter: Miners of the red mountain. Indian Labour in Potosi, 1545-1650. Albuquerque, 1984; Fisher, John: Silver Mines and Silver Miners in Colonial Peru. Liverpool, 1977; Noejevich, Héctor: "La economía del Virreinato del Perú bajo los Habsburgos", Ponencia en el 49 Congreso Internacional de Americanistas, Quito, 1997; Glave, Miguel: "La Sociedad campesina andina a mediados del siglo XVII. Estructura social y tendencias de cambio", Historia y Cultura, Lima, 1990, págs. 81-132; y Sempat Assadourian, Carlos: El sistema de la economía colonial. Mercado interno, regiones y espacio económico. Lima, 1982. Sobre la diversificación de la economía de Chile en el siglo XVII en particular, ver de Ramón, Armando, y Larraín, José: Orígenes de la economía chilena, 1659-1808. Santiago, 1982.

17 JCBL, Santiago de Tesillo: "Guerra de Chile. Causas de su Duración, medios para su fin: exemplicado en el govierno de don Francisco Lasso de la Vega”. Madrid, 1647.

18 Ver, por ejemplo, los pedidos de ganado para las tropas en las Actas del 27 de julio de 1661, 3 de octubre de 1665 y 14 de junio de 1669, Actas del Cabildo de Santiago, tomo VII.

19 Antonio de Mosquera envió a su hermano Luis a España para que consiguiese una autorización para reclutar 1.000 hombres y hacer la guerra "a sangre y fuego", pero cuando Luis llegó a Portobelo "el Virrey le ordenó que con su gente bolviesse a España en guarda del Tesoro Real y plata de particulares, que llevaba el general Alvaro Flores de Quiñones", (JCBL, Aguirre, Miguel: Población de Valdivia. Lima, 1647, foja 33; y Tesillo, "Guerra de Chile...”, foja 69). La mayoría de los hombres de Mosquera era de origen portugués. Según esta fuente, en 1600 una compañía entera de portugueses al mando del capitán Francisco Rodríguez del Manzano fue enviada a Arauco por el gobernador de Buenos Aires; (NL, Alejandro Fuenzalida: La evolución social de Chile, 1541-1810. Santiago, 1906, pág. 92). 
Alonso de Sotomayor: una ruta por tierra desde Buenos Aires a Córdoba y desde allí a Santiago vía Mendoza. ${ }^{20}$ La expedición de Sotomayor no había planeado trasladarse por una ruta terrestre, pero debido al mal estado de salud de sus hombres decidió evitar la azarosa navegación del Estrecho de Magallanes. ${ }^{21}$ Hubo otra expedición antes de la de Mosquera que transitó también la ruta de Sotomayor con hombres y recursos para la guerra en Chile. ${ }^{22}$ Según una carta al rey del propio Sotomayor, esta ruta permitiría llevar caballos del Paraguay hacia Chile donde sus costos eran exorbitantes. A principios de la conquista el precio de un caballo era de 2.000 pesos en oro, pero había bajado a 150 en la primera década del siglo XVII, aunque seguía siendo un costo elevado porque en Córdoba, mientras tanto, su precio difícilmente superaba los 30 pesos. ${ }^{23}$

Para los encomenderos de Santiago, la presencia de las tropas profesionales fue un alivio en cuanto a la defensa armada de la región, aunque su abastecimiento provocó luchas por el acceso y distribución de los recursos naturales del Valle Central. A partir de 1620 el Cabildo fue la arena de discusión de las políticas de importación y del precio de ganado en pie requerido tanto para el alimento de las tropas como para exportar cuero y sebo al Perú. Comerciantes y gobernadores acordaban en el Cabildo de Santiago los cupos y precios del ganado que provenía de las regiones trasandinas. Las actas del Cabildo de Santiago testimonian que eran discusiones arduas porque, mientras los gobernadores reclamaban abundante canti-

20 Sotomayor fue el primero que recorrió completa la ruta Buenos Aires-Santiago, pero ya se usaban algunos tramos. Por ejemplo, se llevaban esclavos desde Córdoba a Chile desde el siglo XVI. El gobernador Quiñones afirmó que las tropas que llegarían a Chile lo harían vía Buenos Aires "porque esta comunicación está ya abierta de tal suerte que andan gran cantidad de carretas por ella" ("Relación del estado del reino..." en Medina, ed.: Colección de Documentos..., pág. 281). Para la expedición de Sotomayor, ver Mariño de Lovera, Pedro: "Crónica del Reino de Chile", en Biblioteca de Autores Españoles. Madrid, 1960, pág. 413; y las fuentes de JCBL, Caro de Torres, Francisco: "Relación de los servicios que hizo a su Magestad del Rey Don Felipe Segundo y Tercero don Alonso de Sotomayor". Madrid, 1620; y Aguirre: Población ..., pág. 33.

21 NL, "Servicios de Cristóbal González, Potosí, 2 de noviembre de 1592", en Anales de la Biblioteca (Buenos Aires), volumen 10, págs. 240-243, reproducido en Schmider, Oscar: "Alteration of the Argentine Pampa in the Colonial Period", Publications in Geography, 2:10, University of California, 1927, págs. 303-321.

22 Se trata de la expedición de Francisco Martínez Leyva. Un acta del Cabildo de Córdoba incluye la carta del gobernador del Río de la Plata, Diego Marín Negrón, al rey del 15 de junio de 1610 en la que informa que Córdoba auxilió a esta expedición que iba a Chile. También Hernandarias de Saavedra informó el 4 de agosto de 1615 que se habían pagado servicios a las tropas de Martínez de Leyva y de Mosquera.

23 Lara, Horacio: Crónica de la Araucania, tomo I, Santiago, 1889, pág. 342; para los precios, ver Encina, Francisco: Resumen de Historia de Chile, tomo I, Santiago, 1956, pág. 136. 
dad de ganado al mejor precio posible para mantener satisfechas a las tropas, los comerciantes exigían cupos restringidos para que no se deprimiese el precio final y de este modo obtener mayores ganancias al exportar sebo y cueros.

Para reducir el conflicto, entre las reformas militares que propuso el gobernador Alonso de Rivera en 1605 estaba el establecimiento de estancias reales pobladas con ganado. ${ }^{24}$ Rivera, cuya relación con una parte de la élite de Santiago nunca fue óptima, trató de desprender al ejército del abastecimiento que pasaba por los mandatos del Cabildo, y por lo tanto, por las decisiones de los principales comerciantes. ${ }^{25}$ No fue posible, sin embargo, abastecer completamente a las tropas con el ganado de las estancias reales, en gran medida porque el abastecimiento era una alternativa económica interesante aunque se ganaba menos que en el mercado peruano. En 1648 el ejército ofreció comprar 6.000 cabezas de ganado a 11 reales cada una, cuando el precio del mercado era de 14 reales. No obstante sabemos que Jerónimo Bahamonde de Guzmán vendió 200 vacas al ejército a ese precio en $1648 .{ }^{26}$ Dos décadas más tarde, el gobernador propuso pagar 20 reales, pero solamente consiguió por ese precio unas 5.400 vacas de las 9.000 que había solicitado, posiblemente debido a que los comerciantes no encontraron del todo apetecible el precio ofrecido por el asiento. ${ }^{27}$

Pero otra parte, sin embargo, el asiento daba la seguridad de cualquier monopolio. Además (y esto era quizás lo más interesante) era una pantalla protectora para importar ganado sin respetar los cupos que establecía el Cabildo de Santiago. El mejor ejemplo lo brinda uno de los miembros de la red de los Toro Mazote. El capitán Gabriel de Toro Mazote compraba yerba mate que llegaba desde el Paraguay y esclavos en Córdoba y poseía tierras en el Valle del Aconcagua, donde el ganado importado desde el este reponía calorías inmediatamente después del cruce de los Andes. Su apoderado en Córdoba era el capitán Francisco Vera Mújica, de acuerdo a un protocolo de 1657. Gabriel también contaba con las tierras de sus parientes Francisco y Luis de Chirinos en Mendoza, quienes eran sus apoderados

24 Sobre las reformas de Rivera, ver Jara, Álvaro: Guerra y Sociedad en Chile. La transformación de la Guerra de Arauco y la esclavitud de los indios. Santiago, 1981, págs. 136 y 143; Campos: Historia de Concepción..., pág. 43; y Góngora: Encomenderos..., págs. 39-40.

25 Un colorido relato de los comportamientos de Rivera en Campos Harriet, Fernando: Alonso de Ribera. Gobernador Galante y Visionario. Santiago, 1966.

26 Acta del 26 de agosto de 1648, en Actas del Cabildo de Santiago, tomo XII.

27 Góngora, Encomenderos..., pág. 108; y actas del 3 de octubre de 1665 y 14 de junio de 1669, en Actas del Cabildo de Santiago, tomo VII. 
para cobrar deudas. En 1678 Luis de Chirinos gozaba de una encomienda de nueve indios (cifra relativamente elevada para Mendoza), figuraba como alcalde en 1681 y registró una veta de plata en la mina de Uspallata. ${ }^{28}$

Un acta del Cabildo de Santiago de 1664 muestra que los cabildantes recelaban de las importaciones de Gabriel Toro Mazote. Entre sus actividades del día, los cabildantes agendaron el cobrar el tercio de las vacas llegadas desde Mendoza, la capital del Corregimiento de Cuyo, antes de que fueran llevadas a los potreros de Gabriel, donde podía continuar con sus transacciones sin la molesta vigilancia del Cabildo. ${ }^{29}$ En 1679 Gabriel era el mayor importador de ganado en Santiago y el ser dueño de potreros en Aconcagua, un punto vital en el cruce de los Andes por el paso de Uspallata-Juncal, le otorgó la posibilidad de imponer una suerte de tributo a los demás importadores que pasaban su ganado por esa ruta. Su conducta desembocó en una agria disputa que estalló en el Cabildo de Santiago en 1679. El Cabildo protestó ante la Real Audiencia que desde "tiempo inmemorial era el paso franco para todos", siendo de este modo el proceder de Gabriel del Toro un acto arbitrario e injusto. Peor para el Cabildo fue cuando en 1680 Gabriel consiguió el asiento de ganado para Arauco que lo autorizaba a ingresar 6.000 cabezas de ganado por año desde Cuyo durante los siguientes dos años. Gabriel podría ahora prácticamente regular el mercado o por lo menos, influir en casi todos los segmentos de la ganadería comercial en Chile. El resto de los miembros de la élite lo sabía y se sintió amenazado, así que la acusación en el Cabildo fue que Gabriel importaba 10.000 cabezas de ganado, el doble de lo que el ejército necesitaba, según los cabildantes, una prueba de que manipulaba el precio del ganado en el mercado de Santiago. Gabriel argumentó que necesitaba importar tantos animales porque debía compensar las bajas ocasionadas por el cruce de la cordillera. El Cabildo presionó al gobernador y hostigó a Gabriel para que abandonase el asiento, pero en vano. ${ }^{30}$ Finalmente los cabildantes recuperaron parte de su poder cuando nombraron corregidor de Aconcagua al capitán Pedro Galindo en 1684. Este reemplazaría al maestre de campo

28 Archivo Histórico de Mendoza, Colonial, Hacienda, Minas, 3; Archivo Provincial de Córdoba, A8, número 1, documento 142; y Espejo, Juan Luis, ed.: La Provincia de Cuyo del Reino de Chile. 2 tomos, Santiago, 1964, tomo II, págs. 291, 405 y 259-268.

29 Acta del 2 de abril de 1664, en Actas del Cabildo de Santiago, tomo XIV.

30 Espejo: Provincia..., tomo II, págs. 259-268; Roa, Luis, y Ursúa: El Reino de Chile, 1535 1810. Valladolid, 1945, pág. 402; Actas del 9 de enero y 13 de setiembre de 1680, en Actas del Cabildo de Santiago, tomo XIX; Archivo Histórico de Mendoza, Colonial, Eclesiástico, documento 278; y Archivo de la Provincia de Córdoba, Escribanos 1, documentos 9, 12, 13 y 142. 
Andrés del Toro, pariente de Gabriel. Si Galindo respondía a los mandatos del Cabildo, controlaría los movimientos de Gabriel y de otros importadores de ganado al mercado de Santiago que cruzasen los Andes por ese paso. Andrés de Toro ingresó al menos 2.000 cabezas en 1679, pero solamente vendió 600 al ejército, según las actas del 7 de abril de 1679 y 15 de junio de 1684. Es interesante que el propio Galindo participara del negocio ganadero, según consta en el acta del 15 de junio de $1684 .{ }^{31}$

\section{Redes inter-regionales: fines del siglo XVI y primera mitad del siglo XVII}

La apertura de la ruta de Sotomayor, desde Buenos Aires a Santiago, fue el cambio más importante de principios del siglo XVII en esta región austral, poco poblada y con escasas posibilidades de progreso material. $\mathrm{La}$ Capitanía General de Chile a principios del siglo XVII, según un informe, tenía "ocho ciudades pobres y poco pobladas". Efectivamente, la capital contaba con no más de unas 200 casas, Mendoza con 32 y San Luis solamente con casi una docena. ${ }^{32}$

La ruta de Sotomayor fue utilizada como quería la Corona, esto es, para facilitar el abastecimiento de las tropas en Arauco. Entre los recursos que transitaron la ruta de Sotomayor en 1608 están 200 indios del Paraguay que fueron enviados a servir como soldados en Arauco. La presencia de estos nativos explica el tránsito de tabaco y yerba mate del Paraguay hacia el sur de Chile, durante el resto del siglo XVII. Quienes mejor aprovecharon esta demanda fueron los jesuitas porque optimizaron las licencias reales, provocando celos en los mercaderes laicos. Los mendocinos se quejaban porque los padres, argumentando que las cargas iban para sus colegios y misiones, evadían impuestos y por lo tanto podían vender estas mercancías, a través de terceros, a un precio inferior. En 1696 la presión de los comerciantes logró abrir una investigación porque se acusó al rector del convento de Mendoza de haber recibido 240 arrobas de yerba mate desde Paraguay, con el encargo de enviárselas al provincial de Santiago, Pablo de Aguilar, quien a su vez enviaría el cargamento al de Lima a cambio de ropa y esclavos para sus colegios y misiones. Sin embargo, las autoridades fue-

31 Actas del Cabildo de Santiago, tomos XIX y XX.

32 Archivo Nacional de Chile, Fondo Claudio Gay, volumen 14, expediente 23, documento 22. 
ron advertidas de que parte de la yerba y tabaco, aparentemente en tránsito, era vendida localmente, a través de una esclava del mismo convento, claro que sin pagar los impuestos correspondientes. El rector de Mendoza, padre José Carrión, se limitó a declarar que "no se han vendido más géneros que los que tenemos de cosecha y la yerba y tabaco que por el vino y aguardiente nos traen de las provincias del Tucumán y Río de la Plata. Estas se venden mientras hay, y todo el tiempo: vino, aguardiente, velas, jabón y pan. Se venden en aposento donde vive una negra". ${ }^{33}$

La circulación de bienes y servicios por la ruta de Sotomayor abrió posibilidades comerciales para colonias pequeñas y periféricas como Mendoza. Fundada en 1561 como parte de la Capitanía General de Chile, desde 1551 había servido como proveedora de mano de obra, indios huarpes, llevados a trabajar a Santiago..$^{34}$ La región había sido visitada en 1551 por Francisco de Villagra cuando, desde el Alto Perú y Tucumán, llevaba 185 soldados, armas y caballos para la guerra en Chile. ${ }^{35}$ Una década después de su fundación, en 1574, se autorizó en Córdoba a un grupo de exploradores comandados por Alonso de la Cámara para que buscasen abrir un camino entre Córdoba y Mendoza que permitiese el tránsito de carretas. Alonso en persona se dedicó a aprovechar comercialmente la ruta CórdobaMendoza. ${ }^{36}$ Pero en general, Mendoza carecía de atractivos para la radicación de españoles así que permaneció despoblada prácticamente hasta la tercera década del siglo XVII. Fue entonces cuando la posesión de tierras para potreros de engorde en el Valle de Uco y Xaurúa, unos 100 kilómetros hacia el sur de la ciudad de Mendoza, comenzó a tener valor económico. Un período húmedo favoreció la existencia de potreros de engorde justo cuando el mercado chileno demandaba vacunos. ${ }^{37}$ Facilitaba además la ocupación de Uco y Xaurúa por parte de españoles el hecho de que las tierras estaban vacantes, porque la mayoría de los nativos había sido llevada a Santiago, muerto por enfermedades, o simplemente huido para evitar tra-

33 Archivo Histórico de Mendoza, Colonial, Eclesiástico, carpeta 278, documentos 58 y 60.

34 En 1552 se entregaron encomiendas en el valle intercordillerano de Uspallata en Mendoza, ver Draghi Lucero, Juan: “Introducción”, en Actas del Cabildo de Mendoza, Mendoza, 1945, tomo I, pág. LIV.

35 Videla, Horacio: "La Evangelización en Cuyo", Investigaciones y Ensayos, 42, Buenos Aires, 1992, págs. 113-134.

36 Lazcano, Arturo: Cabildantes de Córdoba. Córdoba, 1954, pág. 46; y Archivo Provincial de Córdoba, Protocolos, tomo XX, documentos 67, 71, 165, y tomo XXI, documentos 271 у 272.

37 Prieto, María R.: "Formación y consolidación de una sociedad en un área marginal del Reino de Chile: La Provincia de Cuyo en el siglo XVII". Disertación doctoral, Universidad de Sevilla, 1983. 
bajar para los españoles. ${ }^{38} \mathrm{La}$ importancia económica de poseer potreros en Uco y Xaurúa se debe a la necesidad de engordarlo antes del cruce de los Andes por el paso de Piuquenes o Tupungato. Si la cordillera se cerraba temprano, en abril o mayo, era necesario arrendar potreros para la invernada. Francisco de Larrinaga en 1609 arrendó la estancia El Cepillo en Xaurúa para que pastasen 8.500 vacas "hasta que el gobernador disponga de dichas vacas", en tránsito para el ejército en Arauco. ${ }^{39}$

Entre los casos de los primeros propietarios en el Valle de Uco y Xaurúa figura el capitán Gregorio de Puebla, quien llegó a Chile en 1601 y recibió 500 cuadras ( 1 cuadra $=125$ metros $=1,57$ has) en Uco como pago por sus servicios en 1607, aunque en 1605 ya estaba radicado en Mendoza y figuraba como productor de trigo. Alonso de Rivera le donó más tierras, aumentando así sus propiedades. ${ }^{40}$ En 1618 el secretario de cámara Bartolomé Maldonado se sumó a la nómina de los primeros propietarios en Uco. Obtuvo parte de las tierras denominadas "Gelante", solicitadas en merced con el argumento de que tenía "indios en la provincia de Cuyo y para ponerlos en estancia necesitaba 2.500 cuadras de tierra". Tres años más tarde Maldonado dio un poder a los capitanes Alonso de Cepeda y Juan de Amaro para que tomasen la posesión de estas tierras que, en 1632, pasaron a la Compañía de Jesús por un trueque y "gracia y donación pura, perfecta e irrevocable" de 130 cuadras que los padres tenían en La Riquinua. ${ }^{41}$ Uno no puede dejar de preguntarse qué pasó mientras tanto con los indios que supuestamente Maldonado había radicado en esa estancia.

Hacia la tercera década del siglo XVII la propiedad de la tierra en esta región registraba cambios importantes. El capitán Juan de Amaro vendió en 1625 su vasta propiedad en Xaurúa a Jacinto Videla de Guevara, quien habría sido el primero en utilizar intensamente estas 4.000 cuadras para engorde de vacunos. ${ }^{42}$ Fue durante el gobierno de Laso de la Vega (1629-

38 En 1614 el 37\% de los indios que residían en las afueras de Santiago eran huarpes; en Jara, Álvaro: "Importación de trabajadores indígenas en el siglo XVII", Revista Chilena de Historia y Geografía, 124, 1956, págs. 185-199 y 204. En 1622 una orden real prohibió seguir extrayendo huarpes de Mendoza; aunque nadie la respetó. Tres años más tarde, el obispo Francisco de Salcedo intervino con una amenaza de excomunión, que tampoco dio resultado positivo. Para el socorro de los huarpes que se quedaban en Santiago, la iglesia fundó la capilla de San Saturnino; ver Muñoz Cornejo, Humberto: Movimientos Sociales en el Chile Colonial. Buenos Aires, 1945, págs. 112-113.

39 Espejo: Provincia..., tomo II, pág. 491.

40 Roa y Ursúa, Reino..., pág. 568; "Genealogías” (mimeo); Acta del 3 de marzo de 1605, tomo I, en Actas del Cabildo de Mendoza; y Archivo Nacional de Chile, Real Audiencia, decreto de 1612, documento 1892.

41 Archivo Nacional de Chile, Real Audiencia, volumen 847, documento 53.

42 Coria, Luis: Evolución económica de Mendoza en la época colonial. Mendoza, 1988, pág. 94. 
1639) cuando se entregaron la mayoría de las mercedes en esta parte de Mendoza, sin duda en relación con la escasez de tierras para mercedes manifiesta en el relevamiento ordenado a Ginés de Lillo. ${ }^{43} \mathrm{El}$ maestre de campo Domingo Sánchez Chaparro recibió una merced y fue más tarde nombrado teniente corregidor en Cuyo (1646). Una de las misiones que le dio el gobernador fue detener la huida de los desertores de Arauco. Terrateniente en Mellarauco (1639), Domingo vendía comestibles a sus propios soldados. Su poder y relaciones pueden valorarse por el hecho de que, una vez instalado en Mendoza, fue elegido para representar a los productores de vino locales para interponer un recurso ante las autoridades, porque en 1670 Buenos Aires decidió elevar el impuesto a los vinos. ${ }^{44}$ Pero también tenía sus enemigos. Y eran de temer. En 1667 Sánchez Chaparro enfrentó la furia de la Compañía de Jesús, que lo acusó de sacar ganado de las estancias que los padres tenían en Uco y Xaurúa. En enero de 1668 la exasperación del provincial, en su celo por cuidar las posesiones terrenales, estalló en una amenaza de excomunión si Domingo llegaba a sacar alguna pieza de ganado perteneciente a la Compañía. El capitán Andrés Sánchez Chaparro, terrateniente y ganadero en Uco, encomendero en 1695, nuevamente entró en pleito con los jesuitas que lo acusaban de que su ganado en Uco pastaba en tierras que pertenecían a la Compañía. ${ }^{45}$

La red familiar incluía a Manuel, el primer capitán de la milicia de comerciantes de Mendoza, y a su hijo, el maestre de campo Sebastián Sánchez Chaparro que abastecía de cecinas el presidio de Valdivia. La forma en que Manuel amasó su fortuna ejemplifica algunas de las estrategias mercantiles de la región durante la primera mitad del siglo XVII. Arreaba ganado al puerto de Valparaíso y recibía parte de ganado como pago. Con este ganado pobló sus estancias en Mellarauco y Puangue, recibidas en merced. Manuel también vendía vinos a las tropas en Arauco. Al principio, arrendaba viñedos en Chile, pero en 1609 había reunido suficiente capital como para comprarlos en Mendoza. La falta de una encomienda no parece

43 Archivo Nacional de Chile, Real Audiencia, volumen 123, documento 81; volumen 1892, documento 82 ; y volumen 696, documento 847 .

44 Espejo: Provincia..., tomo II, págs. 499-500, 505 y 512-513; y Nobiliario, págs. 723-724 y 850; Roa y Ursúa, Reino..., pág. 556; Archivo Nacional de Chile, Real Audiencia, volumen 123, documento 1616; Archivo Histórico de Mendoza, Colonial, Gobierno, carpeta 40, documento 1 y carpeta 696, documento 737; y Actas del 3 de marzo de 1605 y 4 de agosto de 1670, en Actas del Cabildo de Mendoza, tomos I y II .

45 Archivo Histórico de Mendoza, Colonial, Eclesiástico, carpeta 278, documento 41. 
COMERCIANTES Y REDES MERCANTILES EN LA FRONTERA SUR DEL PERÚ

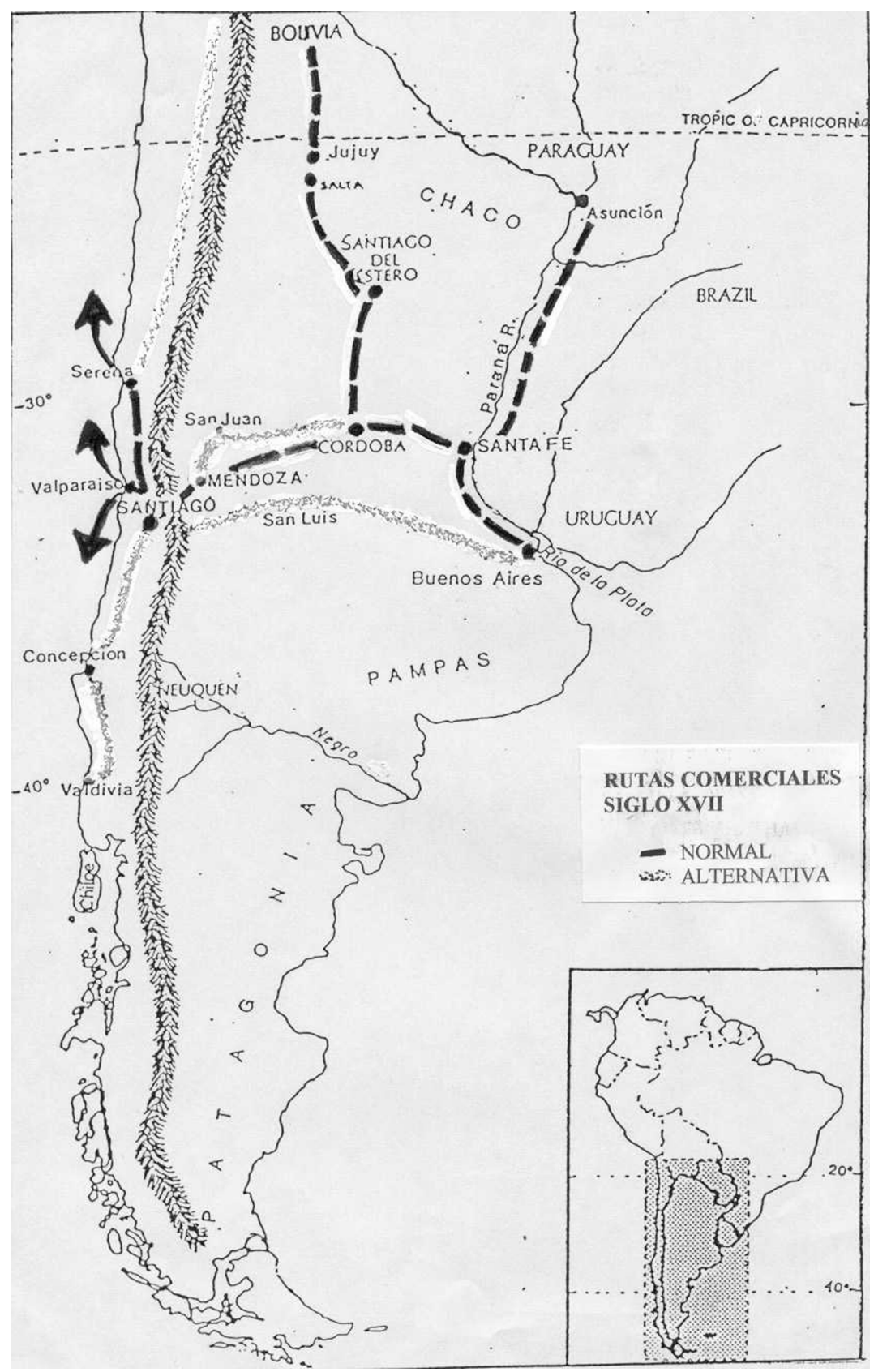


MARGARITA GASCÓN

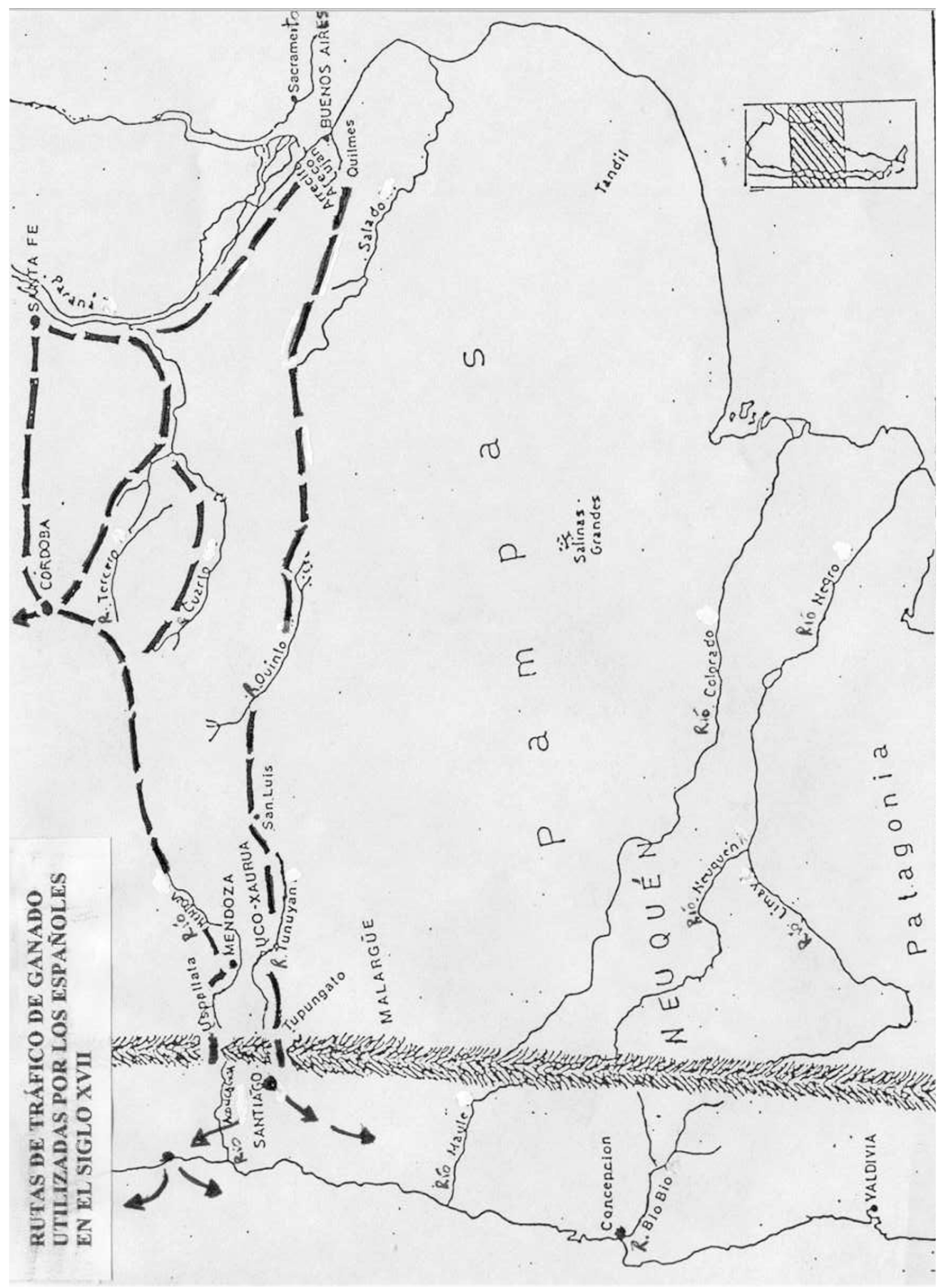


haberlo afectado ya que arrendaba indios huarpes cuyo trabajo pagaba con mercancías. ${ }^{46}$

Otro de los propietarios de potreros en Uco y Xaurúa fue el capitán Pedro Moyano, exportador de ganado a Santiago, quien cerró en 1653, junto con su hermano Antonio, un contrato con el gobernador Antonio de Acuña (1650-1656) por el cual vendían 4.000 cabezas de ganado por un total de 14.000 pesos para el ejército de Arauco. En 1656 volvieron a aceptar venderle al ejército 8.000 cabezas en dos años. ${ }^{47}$ Durante la segunda mitad del siglo XVII siguieron siendo propietarios de potreros, que arrendaban para el engorde de ganado proveniente de Buenos Aires con destino final en Santiago. ${ }^{48}$

Resulta paradójico, sin embargo, que mientras la ganadería de engorde se expandía en Mendoza, los pobres urbanos sufriesen de carestía de carne. La situación llegó a tal punto que el Cabildo debió exigir a los principales ganaderos (denominados los "cuatro señores del ganado") que vendieran parte de su ganado en el mercado local para el abastecimiento de los sectores de escasos recursos. ${ }^{49}$

La ruta de Sotomayor también le permitió a Mendoza comerciar en los mercados de Buenos Aires y Córdoba. Podía enviar vinos y frutas secas y, a su vez, comprar ganado. En 1602 Francisco de Urbina y otros vecinos ya habían sido autorizados a descubrir un camino que uniese Mendoza con el puerto de Buenos Aires para ubicar la producción de vinos. Los primeros en aprovechar la coyuntura favorable fueron el capitán Antonio de Videla, lugarteniente de corregidor, y el capitán Antonio Moyano Cornejo, quien gozaba de una encomienda en Mendoza, pero que por entonces vivía en Santiago. Antonio fue propietario de carretas y bueyes y contaba con las conexiones de sus cuñados en Córdoba, donde vendía trigo, jabón y velas. Enviaba vinos a Buenos Aires y fue quien estableció una posta en Rodeo del Medio en Mendoza, en la ruta de carretas que llevaban vinos, frutas y

46 Espejo: Provincia..., tomo I, pág. 63; y tomo II, págs. 405, 502-504, 514-520 y 723; y Nobiliario..., pág. 850; Coria: Evolución..., pág. 94; Góngora: Encomenderos..., págs. 83, 100 y 166167; Roa y Ursúa: Reino..., pág. 539; Borde, Jean, y Góngora, Mario: Evolución de la propiedad rural en el Valle del Puangue. Santiago, 1956, págs. 49, 55, 225 y 227; Archivo Histórico de Mendoza, Colonial, Gobierno, carpeta 40, documento 1 y Eclesiástico, carpeta 278; y Actas del 20 de diciembre de 1638; 22 de noviembre de 1645; 30 de mayo de 1645 y 9 de abril de 1670, en Actas del Cabildo de Mendoza, tomos II y III.

47 Archivo Nacional de Chile, Real Audiencia, volumen 1299, pieza 2.

48 Arrendaron sus potreros para alimentar 3.400 cabezas de ganado más un número indefinido de novillos nacidos en esos días y que pertenecían al arreo de Roque de San Martín; ver mi artículo "La articulación de Buenos Aires", Anuario IEHS, 13, págs. 202-205.

49 Acta del 19 de noviembre de 1630, en Actas del Cabildo de Mendoza, tomo II. 
cereales hacia Córdoba y Buenos Aires, donde se compraban los productos demandados por los mercados de Santiago y Arauco..$^{50}$

Por su parte, la ciudad de Córdoba fue el nudo central de la ruta de Sotomayor y punto de redistribución de esclavos hacia el norte y hacia el oeste. ${ }^{51}$ Las redes mercantiles que habían traficado principalmente esclavos, se fueron adaptando a lo largo del XVII para satisfacer también las demandas de otras mercaderías. Tan pronto como Sotomayor completó la ruta Buenos Aires-Santiago, los cordobeses enviaron al influyente comerciante Ruy de Sosa a Lima para asegurarle a Córdoba la venta de esclavos en Santiago. El argumento era que el aumento de esclavos permitiría abastecer Santiago de mano de obra, ya que aquella ciudad carecía de encomiendas a partir de la insurrección de los araucanos. ${ }^{52}$ Ruy de Sosa personalmente organizó una compañía en asociación con otro cordobés, Simón Duarte. La compañía con base en Santiago era para criar ovejas y mulas, según dijeron, pero más bien les serviría para traficar esclavos. ${ }^{53}$ Hubo otras sociedades similares, como la que existió entre el capitán Gaspar de Quevedo, ex-alcalde de Buenos Aires, con el encomendero mendocino, Juan Ortiz de Urbina, quien no residía en Mendoza sino en Santiago. ${ }^{54}$

En el circuito mercantil Córdoba-Santiago vía Mendoza figuraba el capitán Bartolomé de Rojas y Puebla, quien vivía en Santiago, pero mantenía conexiones familiares con Mendoza. Su primo Gregorio fue regidor en Mendoza al mismo tiempo que Bartolomé traficaba en la región. ${ }^{55}$ También aparece el canciller perpetuo Alonso del Pozo y Silva, encomendero en

50 Coria: Evolución..., pág. 70; Maza, Juan: Malargüe, Mendoza, 1991; y Morales Guiñazú, Fernando: El comercio colonial en Cuyo. Mendoza, 1938, pág. 7.

51 Assadourian: El tráfico de esclavos...; y "Potosí y el crecimiento económico...”, págs. 169205. Para información sobre la economía regional, ver Garavaglia, Juan Carlos: Mercado interno...; y Economía, sociedad y regiones. Buenos Aires, 1987.

52 Referencias al comercio de esclavos en Santiago en el siglo XVII pueden verse en Dubinovsky, Adela: "El tráfico de esclavos en Chile en el comercio mundial en el siglo XVIII", Boletín Americanista, 23:41, Barcelona, 1991, págs. 291-302.

53 Lazcano: Cabildantes..., págs. 150 y 178; Martínez Villada, Luis: Simón Duarte. Un mercader del siglo XVII. Córdoba, 1937; Archivo Provincial de Córdoba, Protocolos, volumen XXII, documento 568; volumen XXIII, documentos 858, 859 y 861, y volumen XXV, documentos 1114,1115 y 1165; y Acta del 1 de febrero de 1605, en Actas Capitulares de Córdoba, tomo IV.

54 Hasta después de 1640 los Urbina no figuran en documentos emitidos en Mendoza; ver Zuluaga, Rosa: "La trata de negros en la región cuyana durante el siglo XVII", Revista de la Junta de Estudios Históricos, 6:1, Mendoza, 1979, págs. 39-71; Espejo: Provincia..., tomo I, págs. 53 y 63; y Acta del 15 de febrero de 1645, en Actas del Cabildo de Mendoza, tomo II.

55 Zuluaga: "La trata de negros...”, pág. 46; Espejo: Provincia..., tomo I, pág. 63; Roa y Ursúa: Reino..., págs. 568-569 y 571; Coria: Evolución..., pág. 70; y Archivo Histórico de Mendoza, Colonial, carpeta 278 . 
Cuyo, terrateniente en Puangue y tesorero de la Santa Cruzada. ${ }^{56}$ Compraba esclavos y otras mercancías en Córdoba, donde tenía tratos comerciales con Tristán de Tejada, un estanciero con propiedades en Córdoba y Buenos Aires. A principios del siglo XVII Tejada era probablemente el comerciante más próspero de Córdoba. Comerciaba esclavos, vinos, textiles, mulas y vacas, según protocolos notariales ${ }^{57}$ Su red mercantil incluía a Juan Pozo y Silva en Buenos Aires, terrateniente y célebre contrabandista del siglo XVII. Es importante notar que la Corona conocía estos tratos y, en consecuencia, tenía fundados motivos para impedir que miembros de la alta burocracia colonial se involucrasen en asociaciones mercantiles como las anteriores, pero abundan los testimonios documentales del fracaso para implementar las diversas ordenanzas destinadas a combatir la corrupción. Son conocidas las actividades de los contrabandistas Juan de Vergara y Simón Valdés en Buenos Aires en el siglo XVII. La conexión en Córdoba era Simón Duarte. Cuando se "desterró" a Vergara, su destino fue Mendoza. Pareciera que el mismo Vergara hubiese elegido el lugar y el momento ya que, por entonces, otro negrero que operaba en Lima, Manuel de Cardoso, se había instalado en Mendoza. Vergara habría sido un excelente asesor y conexión con Córdoba y con Buenos Aires; podría incluso haber sido su socio. En Mendoza, ambos estaban protegidos por sus vínculos con la familia Carvajal y Saravia, algunos de cuyos miembros ocupaban cargos en Santiago. ${ }^{58}$

Un caso exitoso de comerciante y funcionario es el del capitán Pedro Ome Pesoa, nacido en Chile en 1593, de padre portugués. Fue uno de los pocos oficiales que consiguió un permiso para viajar al Paraguay a comprar ganado para el ejército. Posiblemente no necesitó viajar tan lejos para cumplir con el contrato ya que era pariente de dos familias de importadores de ganado en Chile: los Toro y los Illanes. Andrés Illanes de Quiroga figura

56 Borde y Góngora: Evolución de la propiedad rural..., tomo I, pág. 49; Roa y Ursúa: El Reino..., pág. 533; Retamal, Julio: Familias Fundadoras de Chile, 1540-1600. Santiago, 1992, págs. 605-614; Morales Guiñazú, Fernando: Primitivos habitantes de Cuyo. Mendoza, 1938, pág. 35; y Archivo Provincial de Córdoba, Protocolos, volumen 20, documentos 23, 33, 39 y 40.

57 Archivo Provincial de Córdoba, Protocolos, volumen 21, documentos 387, 388, 490; volumen 27, documentos 609 y 636; volumen 23, documentos 956, 969 y 801; volumen 24, documentos 1076; y volumen 25, documento 1165; para sus vinculaciones políticas, ver Lazcano: Cabildantes..., págs. 75 y 154-189.

58 Lafuente Machaín, Ricardo: Los Portugueses en Buenos Aires. Siglo XVII. Madrid, 1931, pág. 203; Craviotto, J.: Quilmes a través de los años. Quilmes, 1969, pág. 78; Moutoukías, Zacarías: "Burocracia, contrabando y autotransformación de las élites en Buenos Aires en el siglo XVII," Anuario IEHS, 3, 1988, págs. 213-246; Saguier, Eduardo: Mercado Inmobiliario y estructura social. El Río de la Plata en el siglo XVIII. Buenos Aires, 1993, págs. 98 y 155; Zuluaga: "La trata de negros...", pág. 53; y Archivo Provincial de Córdoba, Protocolos, volumen XXIII, documento 838. 
como propietario de ganado y, a su vez, tenía vínculos con Cuyo por ser yerno del general Manuel Fernández Romo. ${ }^{59}$ Además, Pedro tenía una propiedad con ganado en Uco. Ocupó el cargo de corregidor y justicia mayor, lugarteniente del capitán general de Cuyo entre 1628 y 1631, año en que Laso de la Vega le concedió una gran extensión de tierra en Chile. Sus servicios además le permitieron pedir una merced en Buenos Aires, donde continuó con sus actividades mercantiles y políticas, pues fue alcalde (1636-1640) y teniente de gobernador de Santa Fe. En el Río de la Plata se casó con Isabel de Figueroa, la rica viuda de Melchor de Maciel, y en segundas nupcias con la no menos adinerada Catalina de Melo. ${ }^{60}$

\section{Disponibilidad de recursos naturales y adecuación de las redes mercantiles}

A principios del siglo XVII el ganado caballar fue el recurso natural imprescindible para la guerra en Arauco; y para bajar los costos, como vimos, se propuso importarlos desde Paraguay a través de la ruta de Sotomayor. El primer arreo llegó a Chile durante el gobierno de Alonso García Ramón (1605-1610), con una demora de más de dos años. El encargado de la operación fue el capitán Pedro Martínez de Zavala, quien también traía armas (21 arcabuces, 477 hojas de espada, 475 guarniciones y 468 pomos de espada), que habían sido importadas por Mosquera varios años antes. Martínez de Zavala había prometido que conseguiría 1.000 caballos, y atribuyó la demora a que había enfermado en Córdoba, donde contaba con numerosas relaciones ya que fue lugarteniente de gobernador en 1602. Llegaron a Chile solamente 158 caballos que, según informes del ejército, no sirvieron para las acciones bélicas. La importación, en cambio, favoreció a los involucrados en la compra y arreo de los animales, quienes finalmente fueron enjuiciados durante el gobierno de Juan de la Jaraque-

59 Góngora: Encomenderos..., pág. 91; Espejo: Provincia..., tomo II, 514; y Actas del 6 de mayo de 1653, 30 de abril de 1655 y 24 de diciembre de 1670, en Actas del Cabildo de Santiago, tomos XV y XVIII.

60 Roa y Ursua: Reino..., pág. 182; Furlong, Guillermo: Los Jesuitas en Mendoza. Mendoza, 1949: gaveta 4 [documentos en apéndice]; Lafuente Machaín, Ricardo: Los portugueses en Buenos Aires, siglo XVII. Madrid, 1931, págs. 138 y 146; Fuenzalida Correa, Osvaldo: Un linaje chileno de cuatro siglos. Santiago, 1962; y Acta del 14 de diciembre de 1629, en Actas del Cabildo de Mendoza, tomo I. Después de su casamiento en Buenos Aires, Pedro pidió las demasías de las estancias que habían pertenecido a Melchor Maciel. Ver Archivo Histórico de la Provincia de Buenos Aires, ed.: Mercedes de tierras hechas por los gobernadores a nombre del Rey. La Plata, 1979, págs. 127, 145, 178 y 198. 
mada (1611-1612). ${ }^{61}$ A pesar de esta mala experiencia, Jaraquemada insistió en que importar animales del Paraguay era imperioso porque los chilenos se negaban a criar caballos para evitar su robo por parte de los nativos y las requisas por parte del ejército. ${ }^{62}$

De forma similar, la demanda de ganado vacuno para las tropas fue constante porque Arauco nunca pudo salir de su situación de consumidor. Esto por dos motivos. Primero, porque incluso algunos militares se beneficiaban con su abastecimiento, así que las estancias reales languidecían por el abandono y negligencia de los oficiales-comerciantes. Segundo, porque los malones impedían la acumulación de ganado en las estancias reales. Cuando Laso de la Vega llegó a Chile, el jefe araucano Butapichún había destruido 30 haciendas y robado más de 2.000 caballos. El gobernador comenzó por importar aproximadamente 12.000 cabezas de vacuno desde Buenos Aires para repoblar las estancias reales. El 17 de junio de 1631 Laso de la Vega comisionó al capitán Juan Bernardo Jaramillo para esa tarea. ${ }^{63}$ El 31 de enero de 1653 los Moyano Cornejo fueron los beneficiarios del contrato para abastecer al ejército, pero cuando iban a llevarlo a Santiago, entraron en conflicto con el corregidor de Mendoza, Martín de Maguna, quien no les permitió extraer indios para ayudar durante el cruce de la cordillera. El arreo sólo pudo dejar la ciudad de Mendoza en abril y sufrió una tormenta de nieve en la cordillera, muriendo gran cantidad de ganado y algunos peones. En el juicio se reveló que el celo de Maguna nada tenía que ver con proteger a los escasos huarpes todavía radicados en Mendoza, sino con intereses personales, ya que reservaba a esos nativos para que acompañaran sus propias carretas y las de sus favorecidos cuando estas caravanas salieran hacia las provincias de Tucumán y Río de la Plata. Aparentemente el corregidor no tuvo inconvenientes, porque dos años más tarde repitió su comportamiento cuando impidió extraer indios para ayudar

61 Gay, Claudio: Historia física y política de Chile. París-Santiago, 1845-1847, tomo II, pág. 325; Academia Nacional de la Historia, ed.: IV Centenario de las fundaciones de Córdoba y Santa Fe, 1573-1973. Buenos Aires, 1974, pág. 95; Errázuriz, Crecente: Historia de Chile durante los gobiernos de García Ramón, Merlo de la Fuente y Jaraquemada. Santiago, 1908, tomo II, pág. 119; y Archivo Nacional de Chile, Contaduría Mayor, volumen 1612, folio 4.

62 Errázuriz: Historia..., tomo II, pág. 214; Ferrando Keún, Ricardo: Y así nació la frontera. Santiago, 1986, págs. 168-170; Amunátegui Solar, Domingo: La sociedad de Santiago en el siglo XVII. Santiago, 1937, pág. 218; Acta del 24 de enero de 1611, en Actas del Cabildo de Santiago, tomo X; y Archivo Nacional de Chile, Fondo Claudio Gay, expediente 27, volumen 14, documento 24.

63 Latchman, Ricardo: La capacidad guerrera de los araucanos, Santiago, 1915, págs. 63-64; Actas del 20 de febrero y 17 de junio de 1631, en Actas del Cabildo de Mendoza, tomo II; y Archivo Nacional de Chile, Fondo Documental Claudio Gay, volumen 15, documento 2. 
en el arreo de Pedro Moyano Cornejo, quien nuevamente tenía un contrato para llevar ganado al ejército en Chile. ${ }^{64}$

Es menos conocido debido a la falta de fuentes documentales, pero igualmente interesante, el que los indios también aprovecharon las necesidades del ejército para generar sus propias redes y realizar intercambios. Desafortunadamente, las fuentes son fragmentarias, pero hay, sin embargo, una realidad irrefutable y es que la crónica escasez de ganado - que se verifica en los pedidos de los gobernadores al Cabildo de Santiago- debía solucionarse de alguna forma, incluso comprando el ganado a indígenas. En 1661 el gobernador Pedro Porter Casanate se quejó porque de los 24.388 animales que había pedido en tres años, solamente había recibido $14.000 .{ }^{65}$ Es comprensible entonces que un gobernador que debía dar cuenta del estado de sus tropas y de la frontera a la Corona recurriese a cualquier vendedor, incluso sospechando que era ganado robado en estancias de españoles. Hay fuentes del siglo XVIII que aseguran que esto ocurría, ¿habría sido lo mismo en el siglo XVII? Puede pensarse en una respuesta positiva. En 1749 un jesuita afirmó que los españoles de una vertiente de la cordillera no tenían ningún inconveniente en comprar el ganado robado a españoles de la otra vertiente. ${ }^{66}$ Y otro dato sugestivo es que los araucanos no consumían carne vacuna. Según Carrillo de Ojeda, que vivió 46 años en Arauco, los indios "tienen carneros y vacas que usan no para comer, sino para comprar mujeres para casarse. No comen carne que no sea montez" ${ }^{67}$ Es también explícito en cuanto a los fines comerciales y no de consumo interno el oficio de Félix de Azara al virrey. En 1796 aseguraba que "los indios de la falda de la Cordillera tuvieron noticias de los ganados de las pampas y llevaban grandes manadas a Chile, cuyos presidentes tenían contratas de ganado con dichos indios". ${ }^{68}$

64 Morales Guiñazú: Comercio..., págs. 7, 9 y 13; y "Genealogías” (mimeo); Roa y Ursúa: El Reino..., pág. 556; y Acta del 3 de marzo de 1605, en Actas del Cabildo de Mendoza, tomo I. Antonio Moyano fue encomendero en Córdoba y vendió tierra en Mendoza a Juan Ladrón de Guevara; ver Espejo: Provincia..., tomo I, págs. 39 y 63; y tomo II, pág. 405; Coria: Evolución..., pág. 70; Acta del 12 de marzo de 1629, en Actas del Cabildo de Santiago, tomo X; y Acta del 3 de marzo de 1605, en Actas del Cabildo de Mendoza, tomo I. Para el juicio contra el corregidor Maguna, ver Archivo Nacional de Chile, Real Audiencia, volumen 1299, pieza 2.

65 Acta del 17 de julio de 1661, en Actas del Cabildo de Santiago, tomo XVI.

66 NL, Dobritzhoffer, Martín: A Jesuit Missionary in South America. London, 1922, pág. 17.

67 JCBL, Carrillo de Ojeda, Agustín (1603-1671): "Señor. Obligación es, que nacio con el vasallo, dar noticia a su rey, y a sus ministros, que goviernan su monarquía de lo que pide remedio". Madrid, 1659 , foja 2.

68 "Oficio de Felix de Azara al virrey al regreso de su comisión, 31 de julio de 1796", en de Angelis, Pedro, ed.: Colección de Obras y Documentos relativos a la Historia Antigua y Moderna de las provincias del Río de la Plata. Buenos Aires, 1937, tomo VI, pág. 35. 
En esta ruta ganadera del siglo XVII, Córdoba fue también el nudo central y abasteció de ganado en pie a Santiago y Arauco. Según un testigo, Córdoba era el paso obligado de carneros y cabras que desde Cuyo se llevaban a Potosí y de vacunos que se traían desde Santa Fe con destino final en Chile. ${ }^{69}$ Córdoba se favoreció durante varias décadas de los intercambios interregionales por dos motivos: el puerto de Buenos Aires estaba cerrado y la región era abastecida por mercancías desembarcadas en Lima que también llegaban a través de Santiago-Mendoza. Así por ejemplo, en Córdoba y en toda la provincia del Tucumán se vendían cómodamente los vinos producidos en Concepción y las lanas de Arauco. Los vinos de Mendoza y los licores de San Juan todavía ofrecían escasa competencia a los productos que veían del sur de Chile. ${ }^{70}$

Pero la situación de Córdoba cambió desde poco antes de la segunda mitad del siglo XVII, cuando las caravanas y arreos entre Mendoza y Buenos Aires fueron dejando de transitar la ruta de Sotomayor. Preferían internarse más al sur para evadir los impuestos en la ciudad de Córdoba. Para la Corona significó otra prueba del fracaso de la aduana en Córdoba para evitar el drenaje de plata y vigilar el comercio regional. Un informe al Consejo de Indias de 1695 aseguró que el tráfico comercial circulaba por el "camino que va de Buenos Aires al Reino de Chile descubierto (...) por la distancia de 40 leguas que hay desde esta ciudad [Córdoba] al camino referido". ${ }^{71}$ Esta nueva ruta que unía Mendoza con Buenos Aires, vía San Luis, era más barata y más corta, aunque tenía el inconveniente de ser insegura porque la proximidad de caravanas tentaba a los asaltos de los indios. En principio, fue usual que los indios pampas del sur de Córdoba se limitasen a pedir que les "regalasen" vino y otras mercancías para permitir el tránsito por sus territorios. ${ }^{72}$

Las dificultades con los pampas que enfrentasen estas caravanas no preocupó al Cabildo de Córdoba; después de todo, eran caravanas que

69 Vázques de Espinosa, Antonio: Compendio de las Indias Occidentales, Washington, 1948, en Junta Provincial de Córdoba, ed.: Córdoba. Ciudad y provincia, siglos XVI-XX. Córdoba, 1973, pág. 37.

70 Amunátegui Solar, Domingo: "La Capitanía General de Chile hasta la fundación del Virreinato del Río de la Plata", Boletín de la Academia Nacional de la Historia Argentina 9, Buenos Aires, 1936-1937, págs. 227-239; Lara, Horacio: Crónica de la Araucania, tomo I, Santiago, 1889, pág. 344; Góngora: Encomenderos..., pág. 211, y Sempat Assadourian, Carlos, et al.: Argentina de la conquista a la Independencia. Buenos Aires, 1972, pág. 100.

71 Correspondencia de la ciudad de Buenos Aires con los Reyes de España. 3 tomos, Madrid, 1918, tomo 3, págs. 456-457.

72 Acta del 20 de junio de 1664, en Actas del Cabildo de Córdoba, tomo XI. 
evadían impuestos que beneficiaban a esa ciudad. En 1643, sin embargo, las noticias de los movimientos de los pampas en el sur y sus posibles alianzas con araucanos y holandeses, que habían ocupado Valdivia, ocasionaron la alarma del Cabildo. Mientras estaba en San Luis, el militar-comerciante chileno Luis de Toro Mazote, que iba camino a Córdoba donde vendía vinos y compraba esclavos, recibió cartas de su esposa, Catalina de Bustamante. Alarmada por el riesgo que podría estar corriendo Luis, le avisaba del rumor en Santiago sobre una alianza que los holandeses procuraban con los nativos rebeldes para un ataque masivo contra las poblaciones españolas de la región. Cuando llegó a Córdoba, el 8 de diciembre, el Cabildo le obligó a leer sus cartas privadas en una de sus sesiones. Inmediatamente el Cabildo acordó hacer volver a la ciudad a las tropas que iban en refuerzo de la guarnición de Buenos Aires. ${ }^{73}$

En la segunda mitad del siglo XVII la política de los parlamentos iniciada en 1641 en Quillín contribuyó a una cierta calma, aunque no disminuyó la presión sobre los recursos, manteniéndose tanto el número de tropas como su situado. ${ }^{74}$ Aunque no hay acuerdo entre los historiadores sobre el tamaño del ejército debido a que las fuentes son contradictorias, en 1640 había 2.121 soldados que recibían pagos del situado; 215 eran indios. ${ }^{75}$ Pero los holandeses consideraban que había solamente 1.480 soldados españoles en todo Chile. ${ }^{76}$ Otra fuente indica que en 1670 el número ascendía a 2.270 españoles y 429 indios amigos, a pesar de que un decreto del 9 de abril de 1662 prohibió el incremento en el número de tropas. ${ }^{77}$ En otro documento de 1676 se dice que las tropas superaban ampliamente las 2.000 plazas, pero sin embargo, de acuerdo al presupuesto de salarios, había 1.654 soldados (138.936 ducados anuales), 20 capitanes (12.000 ducados),

73 Zuluaga: "La trata de negros...”, págs. 49-50; Acta del 5 de diciembre de 1629, en Actas del Cabildo de Santiago, tomo X; Actas del 15 de febrero y 22 de noviembre de 1645, en Actas del Cabildo de Mendoza, tomo II; y Acta del 8 de diciembre, en Actas del Cabildo de Córdoba, tomo IX. La hacienda del general Luis de Toro figura en la Memoria de la alcabala de 1657, en Actas del Cabildo de Mendoza, tomo III.

74 NL, "Relación verdadera de las paces que capituló con el Arauco rebelado el Marques de Baides, conde de Pedrosa, gobernador y capitán general de Chile y Presidente de la Real Audiencia. Sacada de los informes y cartas y de los Padres de la Compañía de Jesús que acompañaron al Real Ejército en la jornada que hizo para este efecto el año pasado de 1641”, Colección de Libros Españoles Raros o Curiosos, tomo XIII, Madrid, 1642.

75 Ruiz: Los Indios Amigos..., pág. 32.

76 "Nota bibliográfica sobre el viaje de Enrique Brouwer a Chile", Colección Historiadores de Chile, tomo XXXV, Santiago, 1923, pág. 201.

77 Gay: Historia..., tomo III, pág. 280; y Archivo Nacional de Chile, Fondo Claudio Gay, expediente 25 , volumen 16 , documento 55 . 
20 alfereces (4.000 ducados), 15 sargentos (2.160 ducados), 1 coronel (1.800 ducados), y 1 maestre de campo (1.200 ducados)..$^{78}$

Esa calma relativa en Arauco debida a los parlamentos permitió a los araucanos dejar menos hombres en la frontera y cruzar los Andes a buscar ganado en las pampas de Buenos Aires. Por este motivo, la alianza entre los araucanos y los pampas del sur de Córdoba se modificó drásticamente. Los araucanos ya no consideraban a los pampas como aliados para recoger ganado. Esta presencia araucana fue registrada por el Cabildo de Buenos Aires a medida que las vaquerías se internaban hacia el sur; en 1733 el mismo Cabildo reconoció que el ganado salvaje se encontraba en tierras donde dominaban araucanos y pehuenches. ${ }^{79}$

Solamente la alianza entre araucanos y pehuenches se mantuvo en la segunda mitad del siglo XVII. ${ }^{80}$ La razón fue que los principales pasos en la cordillera estaban en territorio pehuenche ${ }^{81}$ Según un informante, se podían usar unos 80 pasos entre Concepción y Sierra Velluda. ${ }^{82}$ El paso del Atuel en el sur de Mendoza era el más transitado por los nativos; el indio José Santos Rodríguez, oriundo del pago de Magdalena en Buenos Aires y lenguaraz de la ciudad de Mendoza, señalaba que este camino no juntaba nieve. Igual información brindó el capitán de milicias Antonio Orsúa:

"había pasado por dicho camino viniendo del cerro Nevado en cuyo tránsito no halló más que unas cinco leguas de cascotería, que lo anduvo en el mes de mayo, uno de los más rigurosos del año, con 3.000 carneros y otros animales, y que jamás había oído decir que caiga por aquel camino nieve alguna, a menos de que fuera un invier-

78 Sobre la vida cotidiana de los soldados, la guerra y otros aspectos de la frontera, ver datos numéricos y ubicación en Archivo Nacional de Chile, Capitanía General, documento 8386; sobre la situación de las tropas, ver Vargas C., Juan: "Estilo de vida en el Ejército de Chile durante el siglo XVII”, Revista de Indias..., LIII:198, 1993, págs. 425-457. Para la influencia de estos aspectos sobre las colonias trasandinas, ver mi artículo, "La articulación de Buenos Aires".

79 La necesidad de ganado y la mención de que se encontraba en territorio indígena se lee en varias actas del Cabildo a partir de la segunda década del siglo XVIII; ver por ejemplo las Actas del 15 de enero de 1723, 10 de febrero, 12 de setiembre de 1725 y 6 de mayo de 1733, en Actas del Cabildo de Buenos Aires, tomo V.

80 En 1655, por ejemplo, organizaron un malón contra las estancias del río Maule en la vertiente occidental de los Andes y luego contra las estancias de los jesuitas en Xaurúa, en la vertiente oriental. Para una crónica sobre ataques de indios a las estancias del sur de Mendoza, ver Canals Frau: Poblaciones..., págs. 536-538; Villalobos, Sergio: Los Pehuenches en la vida fronteriza. Santiago, 1989, pág. 34; Chaca, Dionisio: Tupungato. Buenos Aires, 1941 y Maza: Malargüe..., pág. 31.

81 Según el padre Rosales, entre 4.000 y 5.000 vacunos iban a Arauco por año pasando por los pasos del norte de la Patagonia; en Palermo, Miguel: "La innovación agropecuaria entre los indígenas pampeano-patagónicos. Génesis y procesos”, Anuario IEHS, 3, 1988, pág. 59.

82 NL, Frezier, Amédée (1682-1773): Relation Du Voyage De La Mer Du Sud Aux Côtes Du Chily Et Du Perou, Fait Pendant Les Annes 1712, 1713 et 1714. Paris, 1716, pág. 69. 
no sin ejemplar, por cuyo motivo se había arriesgado a hacer esta experiencia. El señor superintendente agregó, que siendo corregidor de este partido le llegaron unos indios pehuenches en el mayor rigor del invierno (que era el mes de junio) y habiéndoles preguntado por qué camino habían venido, respondieron que se habían dirigido por el boquete del Atuel, para salir al Puente de tierra del río Maule, por la villa de Linares y la ciudad de Chillán, porque jamás habían oído decir a sus antepasados que hubiese nieve por esta entrada o camino, y también se lo habían asegurado varios ancianos de sus parcialidades". ${ }^{83}$

Esta fue la ruta ganadera que utilizaron los indígenas desde el siglo XVII hasta avanzado el XIX.

En la segunda mitad del siglo XVII se fortificó Valdivia tras el ataque holandés, y fue el destino de unos 500 soldados. Los recursos para el abastecimiento debían optimizarse, aunque varias dificultades relacionadas con el aprovisionamiento continuaron sin resolverse. Para empezar, el precio por el ganado ofrecido por el ejército siguió siendo desventajoso en comparación con el precio de mercado. A partir de 1648 el ejército ofreció 11 reales para comprar unas 6.000 vacas, cuando el precio de mercado era de 14 reales. Sin embargo, había vendedores como Lorenzo Núñez de Silva, terrateniente en Colchagua, que vendió 400 de sus animales a ese precio. ${ }^{84}$ Lo mismo sucedía con el precio de los caballos. ${ }^{85}$

Sin embargo, viejas prácticas continuaron vigentes en la segunda mitad del siglo XVII. Algunos seguían aprovechando el asiento para evadir el control del Cabildo. En 1657 cuando el Cabildo le ordenó vender al ejército el tercio del ganado introducido desde Uco, Bernardino de Urbina respondió que él había arreado solamente 3.300 vacas en lugar de las 4.500 que el Cabildo aseguraba que tenía. Argumentó que ni siquiera disponía de ese ganado porque ya lo había vendido, así que en dos meses podría vender al ejército su cupo de 500 animales. Vendieron al ejército, en cambio, el tercio de su arreo de casi 2.000 cabezas de ganado traídas desde Buenos Aires, el capitán chileno Pedro Fuentes y su socio el capitán porteño Roque de San Martín. ${ }^{86}$

Debido a que el número de soldados seguía siendo elevado, el abastecimiento seguía siendo prioridad en la agenda de los gobernadores y motivo de tensiones con el Cabildo. Cuando Pedro Porter Casanate llegó a Chile

83 NL, Sourryere de Souillac, J.: Descripción Geográfica de un nuevo camino de la gran cordillera para facilitar las comunicaciones de Buenos Aires con Chile. tomo VI, Buenos Aires, 1937, pág. 31.

84 Acta del 26 de agosto de 1648, en Actas del Cabildo de Santiago, tomo XII.

85 Archivo Nacional de Chile, Capitanía General, volumen 715, documentos 8344 y 8389 ; para precios, ver Góngora: Encomenderos..., pág. 108.

86 Actas del 3 y 8 de agosto de 1657, en Actas del Cabildo de Santiago, tomo XV. 
después del levantamiento araucano de 1655 encontró una frontera inestable. En consecuencia, pidió más ayuda a Santiago: 9.000 cabezas de ganado para poder salir de campaña. El Cabildo leyó el pedido del gobernador en la sesión y lo sintetizó en el acta; cuando D. Pedro anunció que iniciaba su expedición contra los rebeldes araucanos, el Cabildo respondió que apoyaba la empresa...jobligando a todos los conventos de la capital a rezar por el buen fin de la campaña militar! Sin duda que el gobernador quería más que apoyo moral por parte del Cabildo. En 1660 Porter le envió otra carta, apelando a la compasión de los cabildantes por el deplorable estado de las tropas en la frontera; éstos aprovecharon la oportunidad y enviaron la carta al virrey como prueba del empobrecimiento en que vivía la colonia y conseguir así la reducción de impuestos. Tuvieron éxito porque la Corona terminó eximiendo a Santiago de pagar el impuesto de la unión de las armas. Por su parte, el gobernador comprendió que debía dejar de esperar ayuda de Santiago y procedió a llevarse las guarniciones que protegían las espaldas de la capital en el río Maule. ${ }^{87}$

El último gobernador del siglo, Tomás Marín de Poveda (1692-1700) era optimista en 1695 porque Arauco parecía completamente pacificado, aunque el ejército debía seguir vigilante, sobre todo por la amenaza de corsarios y el aumento del contrabando. ${ }^{88}$ Poveda consiguió caballos cuando los solicitó, pero tuvo severas dificultades para abastecerse de trigo. La novedad durante la segunda mitad del siglo son las reclamaciones de los gobernadores por la escasez de granos, que aumentó incluso después del terremoto de Perú. El 8 de junio de 1656 el Cabildo decidió que el gobernador debía resolver el transporte del cereal a la frontera porque era difícil y caro embarcarlo desde Valparaíso a Concepción; estableció que se debía pagar 10 pesos a cada carreta que llevaba cereal desde Santiago al puerto de Valparaíso e incluso sugirió al gobernador que se reactivara la producción cerealera de las estancias reales en Melipilla, Llipeo, Lampa, Cuminón y Aconcagua.$^{89}$ En cierta medida, los precios en Chile durante la segunda mitad del siglo XVII fueron el resultado de la inflación que afectó a toda la economía del imperio. En el Valle Central, la escasez de algunos productos

87 Archivo Nacional de Chile, Fondo Claudio Gay, expediente 24, volumen 15, documentos 14 y 17; Actas del 5 de enero, 13 de febrero, 25 de junio y 8 de julio de 1660, en Actas del Cabildo de Santiago, tomo XVI. La relación entre el gobernador y el Cabildo puede seguirse detalladamente a través de las actas de las reuniones efectuadas durante octubre de 1665, en Actas del Cabildo de Santiago, tomo XXVII

88 Archivo Nacional de Chile, Fondo Claudio Gay, expediente 45, volumen 36, documento 4.

89 Actas del 6 de diciembre de 1652, 8 de junio y 22 de agosto de 1656, 15 de marzo y 20 de junio de 1657; y 3 de agosto de 1658, en Actas del Cabildo de Santiago, tomos XIV y XV. 
se aceleró al ritmo de la inflación y la presión fiscal se hizo más notoria. El impuesto de la unión de armas, por ejemplo, pasó del $2 \%$ al $4 \%$ en $1645 .{ }^{90}$ La exportación de cereales al Perú aumentó después del terremoto de 1687. Según explicó varios años después Carlos Darwin, este terremoto había cambiado el curso de los ríos en Perú en áreas dedicadas a la agricultura cerealera, con su consecuente deterioro. Comenzó a establecerse un patrón de larga duranción, ya que el trigo producido en las haciendas de la zona central de Chile abastecería a los mercados de la costa peruana durante la primera mitad del siglo XVIII. ${ }^{91}$

En cuanto a las actividades mercantiles vinculadas a la frontera en Arauco, en la segunda mitad del siglo XVII siguen los casos de militarescomerciantes que operaban localmente: Ignacio de la Carrera, gobernador de la isla de Chiloé, utilizó su poder para monopolizar la exportación de maderas, y todavía gozaba de 21 indios encomendados en 1655, año en que se le nombró corregidor de Santiago. ${ }^{92}$ Diego González Montero es otro ejemplo: gobernador de Valdivia en 1650 y dos veces gobernador interino de Chile. Los 27 puelches de su encomienda trabajaban en las tierras localizadas cerca de las minas de Marga-Marga. Incorporó más tierras a su patrimonio a través de la dote de su segunda esposa, aunque su mejor momento económico se debió a la asociación con Florián Ramírez de Montenegro, terrateniente en Colchagua, donde tenía ganado, viñedos y una talabartería. La fuerza de trabajo se proveía de esclavos. ${ }^{93}$ Sin embargo, los importadores de ganado en pie a Santiago desde Buenos Aires debieron seguir operando dentro de inter-redes. El maestre de campo Felipe de Arce compraba ganado en Buenos Aires y lo engordaba en su estancia de Colchagua o en Uco. En Buenos Aires aprovechaba para colocar vinos que transportaba en sus pro-

90 El impuesto fue parte del programa del conde duque de Olivares para la defensa militar del imperio. Santiago trató de quedar eximida, alegando que ya había contribuido demasiado a la defensa del imperio desde los primeros días de la presencia española en la región, pero a partir de 1640 debió pagar la unión de las armas.

91 Sobre esta nueva economía, ver Ramos, Demetrio: "Trigo chileno, navieros del Callao y hacendados limeños entre la crisis agrícola del siglo XVII y la comercial del siglo XVIII", Revista de Indias, 26:105-106, 1966, págs. 209-222. Como ejemplo de las dificultades en aprovisionar al ejército con trigo, ver "Causa contra Francisco García Sobarzo y otros sobre la provisión de trigos, conducción del situado y otras materias, 1697," Archivo Nacional de Chile, Real Audiencia, volumen 593 y 437 (incompleto); Gay: Historia..., pág. 332, y Amunátegui: Sociedad..., pág. 151.

92 Góngora: Encomenderos..., pág. 157; Espejo: Nobiliario..., pág. 214; Ferrando: Y así nació la frontera..., pág. 226; y actas del 30 de abril de 1655 y 20 de junio de 1657, en Actas del Cabildo de Santiago, tomo XV.

93 Amunátegui: Sociedad..., pág. 59; Ferrando: $Y$ así nació la frontera..., pág. 223; Góngora: Encomenderos..., págs. 147-148 y 152; y actas del 11 de diciembre de 1620 y 20 de junio de 1657, en Actas del Cabildo de Santiago, tomos VIII y XVI. 
pias carretas. Para realizar todas estas actividades en colonias tan alejadas entre sí, contaba con las relaciones de su poderosa red de parientes, descendientes de conquistadores: los Cabeza de Vaca por línea paterna y los Verdugo por línea materna. ${ }^{94}$

La red de los Toro Mazote siguió expandiéndose cuando Andrés de Toro Mazote se radicó en Cuyo para aprovechar tanto su encomienda como las 4.000 cuadras en San Luis, uno de cuyos linderos daba a la ruta de carretas que transitaban hacia Córdoba. Manuel de Toro Mazote fue miembro del Cabildo de Santiago (desde 1612 a 1661) y tenía huarpes trabajando en su estancia de Aconcagua y Quinteros. A partir de 1651 comerció con Lima en asociación con Tomás Cascos y además explotaba las minas de San Lorenzo en el Valle de Uspallata en Mendoza. Un documento firmado en Córdoba por Marcos Toro Mazote, junto con un poder dado al capitán José Francisco Vargas, testifican los vínculos comerciales de miembros de esta familia con la provincia del Tucumán..$^{5}$

En cuanto al ganado vacuno, el mercado de Santiago continuó absorbiendo un alto número de animales ya que exportaba alrededor de 18.000 quintales de sebo por año al Perú; aunque en 1663-1664 la cifra llegó a 30.000 quintales. ${ }^{96}$ Se calcula que una vaca provee aproximadamente de un quintal de sebo, de modo que la necesidad de importarlo era fundamental tanto para mantener ese circuito como para satisfacer las demandas de Arauco. El ejemplo más interesante de gran importador de ganado en pie lo brinda el capitán Antonio de Barambio: nacido en Bilbao en 1580, era terrateniente en Lampa y Colina en Chile, importaba ropa desde Perú que enviaba luego a Buenos Aires donde, a su vez, compraba el ganado que vendía en Santiago. Las importaciones de ganado desde Buenos Aires y San Luis las realizaba asociado con el escribano Gerónimo de Ugas, a través de una compañía que operaba con un capital de 62.000 pesos al que Barambio posiblemente pudo sumar los 46.779 pesos en tierras y esclavos que recibió

94 Góngora: Encomenderos..., pág. 155; Espejo: Provincia..., tomo I, pág. 106; y Coria: Evolución..., pág. 70.

95 Roa y Ursúa: Reino..., pág. 402; Góngora: Encomenderos..., págs. 91 y 168-169; Espejo: Provincia..., tomo II, págs. 405, 540 y 546-547; Morales Guiñazú: Primitivos..., pág. 3; acta del 1 de abril de 1644 y 20 de junio de 1657, en Actas del Cabildo de Santiago, tomos XII y XVI; Archivo Nacional de Chile, Archivo de Escribanos, volumen 343, folio 161; Archivo Histórico de Mendoza, Colonial, Hacienda, carpeta 96, documento 22; y Gobierno, carpeta 29; y Archivo Provincial de Córdoba, Escribanos 1, Libro 1, documentos 72, 74, 110 y 481.

96 Mellafé, Rolando: La introducción de la esclavitud negra en Chile. Santiago, 1969, págs. 168-169; Amunátegui: Sociedad..., tomo I, pág. 47; tomo II, págs. 240-241; y actas del 30 de mayo, 5, 10 y 15 de octubre de 1664, en Actas del Cabildo de Santiago, tomo XVI. 
como dote de su esposa. En 1655 figuraba entre los que tenían ganado en el radio de doce leguas de Santiago y debían, por orden de la Real Audiencia, abastecer al mercado; en 1657 estaba en la nómina de importadores de ganado desde Cuyo, y por lo tanto, entre quienes debían vender 315 cabezas que correspondían al tercio al ejército. En Córdoba, el capitán Domingo de Burgos operaba en su nombre. Tampoco le faltó participación en la vida política local ya que fue alguacil mayor de Santiago en 1640 y alguacil de Concepción en 1646. ${ }^{97}$

El volumen de la actividad comercial con ganado que seguían teniendo los mercados chilenos en la segunda mitad del siglo se aprecia también en el testamento del capitán Lorenzo Suárez, regidor en 1643 y después corregidor en la estratégica zona de Aconcagua, a lo que sumó el asiento en Valdivia en 1651. En su testamento declaró que en la talabartería de su propiedad se producían alrededor de 10.000 cueros anuales, un alto número que prueba la disponibilidad de vacas en el mercado local. ${ }^{98}$

Una consecuencia de esta voracidad de recursos de los mercados en Chile fue la extracción sostenida de ganado de las pampas argentinas. La tendencia se notó primero en el agotamiento de los cimarrones del sur de Córdoba y de Santa Fe. En Buenos Aires era solamente una cuestión de tiempo. La extracción de ganado en los alrededores del puerto fue intensa en el siglo XVII para poder pagar por las mercancías introducidas legal o ilegalmente y para su exportación. ${ }^{99}$ Pero el puerto podía aprovechar el abundante ganado de las proximidades sin atender a las cacerías ilegales de quienes se internaban hacia sus pampas del sur. Sabemos que los vecinos de Córdoba y de Chile (incluyendo Mendoza) al igual que los araucanos, pehuenches y pampas realizaban vaquerías desde posiblemente la cuarta década del siglo XVII

97 Roa y Ursúa: Reino..., pág. 665; Góngora: Encomenderos..., págs. 94-96 y 156; Silva, Fernando: Tierras y pueblos de indios en el Reino de Chile. Santiago, 1962, pág. 75; y actas del 1 de abril de 1644, 20 de junio y 3 de agosto de 1657 y lista de proveedores de 1655, en Actas del Cabildo de Santiago, tomos XII y XVI; para sus actividades en Córdoba, Archivo de la Provincia de Córdoba, Escribanos 1, Protocolos, documentos 126 y 129.

98 Góngora: Encomenderos..., pág. 168; y Actas del 1 de abril de 1644 y 20 de junio de 1656, en Actas del Cabildo de Santiago, tomos V y XV.

99 La abundancia de ganado en los alrededores del puerto todavía fue registrada por Acarete du Biscay a fines del siglo XVII en su relato Voyage du Sr Acarete à Buenos Ayres sur la Rivière de la Plate e delá au Perou. Paris, 1672. Otro testimonio lo brinda el padre Cayetano Cattaneo, quien en 1729 aseguraba que las naves españolas cargaban a su regreso 40.000 y 50.000 cueros; número al que se sumaban los cueros sacados por contrabando, calculando así que se matarían alrededor de 80.000 animales para conseguir los 50.000 cueros de calidad, también llamados "de medida" (NL, "Primera carta del padre Cayetano Cattaneo de la Compañía de Jesús a su hermano José, de Módena, Buenos Aires, 18 de mayo de 1729"). 
debido a que el Cabildo de Buenos Aires no vigilaba la zona. Este dato cronológico lo tenemos debido a la disputa entre los Cabildos de Buenos Aires y Córdoba que desembocó en un juicio de 1704. Un documento de 1659 en defensa de los intereses de Buenos Aires aseguraba que el ganado que pastaba en Córdoba en realidad pertenecía a Buenos Aires porque era el ganado que había sido robado del sur de su jurisdicción por vecinos de Chile. ${ }^{100}$

La presión por acceder al cada vez más escaso recurso ganadero de las pampas argentinas fue también causa de enfrentamientos entre los Cabildos de Mendoza y Córdoba. El procurador del Cabildo de Mendoza en 1691 llevó adelante la defensa de los derechos de los mendocinos a vaquear en el sur de Córdoba y de Buenos Aires. El argumento fue que debido al abandono de las estancias por los malones de la segunda mitad del siglo XVII, el ganado de los mendocinos se había dispersado buscando los pastos y las aguadas de las pampas cordobesas y porteñas. Con el mismo argumento, el capitán mendocino Gregorio de Guevara solicitó una licencia de vaquería ante el Cabildo de Mendoza, pero que abarcaría incluso parte de la jurisdicción del Cabildo de Córdoba. ${ }^{101}$ Todo indica que las vaquerías debían internarse cada vez más hacia el sur, hacia el territorio indígena, donde todavía podían encontrarse cimarrones. A principios del siglo XVIII, el capitán Juan Luis Ladrón de Guevara murió en una vaquería que se había internado tan al sur, según una fuente, que había llegado a divisar la mítica Ciudad de los Césares. Juan Luis era un importante ganadero, propietario de la estancia Moco en Uco, que había comprado a Jacinto de Videla. ${ }^{102}$

De todos los conflictos en esta periferia del virreinato del Perú por acceder a ganado cimarrón hacia fines del siglo XVII, el más largo y eno-

100 Archivo General de la Nación, Sala IX, expediente 2, legajo E2, Tribunales; Archivo Provincial de Córdoba, Gobierno, "Notas del Cabildo de Buenos Aires sobre robo de ganado", Carta al Cabildo de Córdoba, 11 de agosto de 1704, volumen 3, documento 8; y Acta del 28 de junio de 1704, en Actas del Cabildo de Buenos Aires, tomo I. Nuevamente en 1709 el Cabildo denunció que los vecinos de Cuyo, Tucumán y Santiago del Estero extraían ganado ilegalmente del sur de Buenos Aires. Para esa fecha, el Cabildo prefería comprar sal a los indios pampas antes que favorecer a los comerciantes cordobeses; ver Moya, Juan: Contribución a la Historia de Bragado. La Plata, 1957, págs. 7-8; Kossok, Manfred: El Virreinato del Río de la Plata. Su estructura económico-social. Buenos Aires, 1972, págs. 82 y 83; Archivo General de la Nación, Sala IX, Guerra, volumen 2, documentos 62 y 240; y Acta del 17 de febrero de 1717, en Actas del Cabildo de Buenos Aires, tomo III. Sobre la extracción de sal en el sur de Buenos Aires en relación con los nativos y con los cordobeses, ver Auto del 27 de agosto de 1720 del gobernador Bruno de Zavala, Archivo General de la Nación, Sala IX, Tribunales, expediente 7, legajo D1.

101 Archivo Histórico de Mendoza, Colonial, Gobierno, Informe del 15 de febrero de 1691, carpeta 22 , documento 12 ; y carpeta 11 , documento 12 .

102 Figuraba entre los grandes propietarios de carretas, ver Coria: Evolución..., pág. 70; y terrateniente en Uco, ver Espejo: Provincia..., tomo II, pág. 513; sobre las circunstancias de su muerte, ver Archivo Histórico de Mendoza, Colonial, Gobierno, carpeta 5. 
joso fue por el derecho a vaquear en la Banda Oriental que enfrentó a porteños, santafecinos y jesuitas de las misiones paraguayas. ${ }^{103}$ En los primeros años de la segunda década del siglo XVIII se fijaron las cuotas de extracción de ganado vacuno de la Banda Oriental, que se agotó rápidamente. Por entonces el Cabildo de Buenos Aires buscaba revertir la decidida tendencia al agotamiento de ganado cimarrón de sus pampas del sur. Entre sus medidas estaba la vigilancia con patrullas armadas para que vecinos y/o nativos de otras jurisdicciones no cazasen y una estricta vigilancia sobre el volumen de los embarques de cueros. ${ }^{104}$

A pesar de las limitaciones que iba imponiendo el agotamiento del ganado cimarrón, la ganadería comercial se mantuvo como la principal actividad económica entre las colonias de esta región. También en el rubro de la ganadería comercial, la red más eficiente fue la de los jesuitas, y aunque no la reconstruyamos completamente en este trabajo, es importante brindar un mínimo de información que dé cuenta del volumen de bienes que circularon entre sus colegios y conventos, aunque en gran medida se volcaron en los mercados. Desde el Paraguay a Chile, los jesuitas conducían ganado vacuno a través de sus amplias estancias de Córdoba hasta el Valle de Uco y Xaurúa; o desde el Río de la Plata hasta la estancia de Nogalí en San Luis. Acumularon tierras en Uco y Xaurúa durante el siglo XVII por donaciones de particulares, de gobernadores, o por trueques y compra. En 1704 la contabilidad de la estancia de San José de Uco señaló más de 3.000 cabezas de ganado, carretas, sebo y fuerza laboral de 151 esclavos. En la cercana estancia de La Arboleda, de 54.432 cuadras, se contabilizaron más de 12.000 animales. ${ }^{105}$ Una estadística oficial de 1701 señaló que habría en total unas 40.000 cabezas de ganado en Uco, Xaurúa y Llacorón, de modo que la suma del ganado pastando en estas dos estancias de los jesuitas indicaría que poseían casi el $40 \%$ del ganado disponible en la zona. ${ }^{106}$

103 Finalmente el Cabildo de Buenos Aires negoció las cuotas de extracción de ganado de la Banda Oriental con santafecinos y jesuitas, ver actas del 26 de agosto y 6 de setiembre de 1724; 3 de marzo, 1 y 3 de abril de 1726 y 1 de diciembre de 1730, en Actas del Cabildo de Buenos Aires, tomos IV, V y VI; y Coni, Emilio: Historia de las vaquerías del Río de la Plata, 1555-1750. Madrid, 1930 [1. ${ }^{\mathrm{a}}$ ed.], Buenos Aires, 1979, págs. 48 y 49.

104 Sobre la vigilancia a los embarques, ver casos en Pinasco, Eduardo: Hombres de la Historia del puerto de Buenos Aires en el período colonial. Buenos Aires, 1972, págs. 175, 177-178 y 182.

105 Chaca: Tupungato..., págs. 120, 123, 141-142 y 166-167; Enrich, Francisco: Historia de la Compañía de Jesús en Chile. Barcelona, 1891, tomo I, págs. 281, 501 y 724; Archivo Histórico de Mendoza, Colonial, Eclesiástico, carpeta 278; y Acta del 3 de setiembre de 1644, Actas de Cabildo de Mendoza, tomo II.

106 Archivo Histórico de Mendoza, Colonial, Gobierno, carpeta 12, documento 2. 


\section{Conclusión}

La revuelta de los araucanos de 1598-1599 transformó a Chile, pero también afectó a toda la región de la periferia sur del virreinato peruano. La causa de la transformación se relaciona con el establecimiento del ejército profesional porque creó un mercado consumidor importante para las limitadas economías de los asentamientos españoles de esta región de Indias. La apertura de la ruta de Sotomayor a principios del siglo XVII, hecho ligado a la frontera con Arauco, fue un primer paso en la transformación porque permitió el flujo de mercancías desde lugares tan lejanos como el Río de la Plata y Paraguay hacia Chile. Sucesivamente, las principales colonias de la zona recibieron la influencia económica de Arauco ya que por esta ruta transitaban los recursos materiales y humanos que demandaba Chile. Las redes mercantiles basadas en el parentesco fueron vitales para el éxito de las empresas de numerosos comerciantes, con excepción de la Compañía de Jesús que operaba con una admirable eficacia corporativa.

En Santiago, los terratenientes y encomenderos se beneficiaron con la instalación del ejército profesional y con su situado que fue la base del crédito; la élite pudo olvidarse de las obligaciones de la defensa, mientras mantenía el acceso a encomiendas, o esclavizaba indios de guerra. Además comenzaría a beneficiarse comercialmente pues nada despreciable fue el volumen de recursos que absorbía Arauco: caballos, vacas, vinos, cereales, municiones, vestimenta, cueros, aperos. De modo que una amplia mayoría de los habitantes de Santiago se relacionó con las actividades del abastecimiento, aprovechando vínculos militares y políticos junto con redes familiares extensas. El capitán Alonso de Campofrío, como tantos otros militares-mercaderes, tenía huarpes que trabajaban sus tierras en la estancia de La Ligua mientras que su yerno, el ya conocido capitán Antonio de Barambio, importaba ganado desde Buenos Aires y San Luis "en grandes expediciones", según el testamento de Campofrío en 1662. ${ }^{107}$ Realizar estas grandes empresas en el siglo XVII era posible por la seguridad que brindaban las operaciones realizadas dentro de redes de parentesco que extendían la acción individual de una alejada colonia a otra, a través de rutas carentes de seguridad.

107 Roa y Ursúa, Reino..., págs. 301-302 y 665; Silva: Tierras..., pág. 75; Espejo: Nobiliario..., págs. 230-231; y actas del 23 de setiembre de 1587 y 2 de setiembre de 1643, en Actas del Cabildo de Santiago, tomos V y XII. 
De manera similar, en el clan de los Lisperguer, Nicolás — que tenía el título de capitán desde 1655 - exportaba sebo a Lima y vendía carne seca al presidio de Valdivia. Su red familiar incluía a los Hinestrosa, negreros que operaban en Buenos Aires. Acumuló cargos políticos y militares (incluso pidió su ingreso en una orden militar) sin dejar por ello de manejar sus negocios. ${ }^{108}$ No fueron unos pocos casos aislados ni excepcionales y aun con variaciones para la primera y segunda mitad del siglo XVII permiten apreciar las posibilidades para el comercio que otorgó la frontera con Arauco. De ahí que la Corona estaba haciendo el trabajo de Sísifo al mantener un ejército profesional con pagos del situado, porque convertía la situación de guerra en un interesante negocio en una región donde había pocas posibilidades económicas. Además, el que la actividad mercantil tuviese la dinámica que hemos descrito transformaba a la agenda político-militar de la Corona en un buen negocio de familias a la hora de implantarla localmente.

Arauco había sido la sección más prometedora de la conquista de Chile, tanto por el número de nativos como por los beneficios de su fertilidad, pero la revuelta araucana truncó las expectativas de expansión, limitando a los colonos a explotar los recursos del Valle Central. Si los recursos naturales hubiesen sido abundantes en Chile es posible que las redes mercantiles hubiesen permanecido en una escala local (intra-redes). Pero su limitado número junto con el aumento en la demanda provocado por el establecimiento del ejército impulsó el comercio a escala interregional (inter-redes) uniendo a comerciantes de Santiago con Mendoza, Córdoba y Buenos Aires. Los parlamentos a partir de 1641 poco aliviaron los gastos de guerra y la presión sobre los recursos. En la segunda mitad del siglo XVII el aumento de la exportación de cereales al Perú sumó este rubro a las dificultades de abastecimiento de las tropas.

El resultado de la presencia del ejército real en Arauco fue favorable económicamente para Santiago, que fue la primera y principal colonia que aprovechó las demandas de bienes y servicios del ejército en Arauco. En cuanto a Mendoza, posiblemente hubiese continuado semiabandonada por las escasas posibilidades comerciales; pero al quedar dentro de la ruta de Sotomayor, quedó integrada en la ruta del flujo de recursos SantiagoCórdoba-Buenos Aires/Paraguay. Incluso cuando se comenzó a transitar la ruta San Luis-Buenos Aires, Mendoza ya tenía asegurado su lugar en esta economía periférica gracias a los potreros de engorde de Uco y Xaurúa.

108 Góngora: Encomenderos..., págs. 91, 149-150 y 160-162; Amunátegui: Sociedad..., pág. 58; y acta del 31 de diciembre de1587, en Actas del Cabildo de Santiago, tomoV. 
Por su parte Córdoba tenía una situación privilegiada al ser el nudo central de las rutas de flujo de recursos. Aun cuando muchas caravanas dejasen de transitar la ruta de Sotomayor y se internasen al sur para llegar a Buenos Aires vía San Luis, Córdoba siguió siendo el lugar de paso de los productos que bajaban desde Paraguay. Desde Córdoba se distribuyeron esclavos, ganado, yerba mate y tabaco durante todo el siglo XVII.

Más difícil en cambio es medir el impacto económico del ejército profesional instalado en Arauco en el puerto de Buenos Aires. Desde el punto de vista de las cacerías ilegales efectuadas por vecinos de Chile y nativos, el saldo es negativo ya que contribuyeron a acelerar el agotamiento del cimarrón. De todas formas, hubo un beneficio muy concreto para Buenos Aires porque aprovechó la situación de Arauco para presionar a la Corona. A principios del siglo XVII le vino bien al Cabildo porteño el recordar que era en Buenos Aires donde desembarcaban las tropas llegadas desde España con destino en Chile. Tan temprano como en 1606 la Corona intentó suprimir la posibilidad de comerciar con las colonias portuguesas debido al descarado contrabando. El Cabildo amenazó con que Buenos Aires se despoblaría y que por lo tanto quedaría en peligro todo el sistema defensivo del sur, ya que no habría puerto atlántico en el que desembarcar las tropas que protegerían las espaldas del virreinato peruano. La amenaza hizo retroceder a la Corona que se vio obligada a establecer una aduana en Córdoba que infructuosamente procuró evitar el drenaje de plata potosina. Hay evidencia documental de 1660 que indica la abundancia de ganado salvaje en los alrededores de Buenos Aires como explicación de su riqueza. Un informe a Colbert calculaba unas 6.300 almas, con unos 700 hombres en la guarnición, [campos] "cubiertos de una multitud increíble de caballos y toros, casi todos salvajes, que no valen en Buenos Aires más que un escudo por pieza". Y lo más interesante es que agregaba que "corre mucho dinero que viene del Perú, en patacones, barras de plata y piñas de plata virgen y de Chile vienen lingotes y ladrillos de oro", una afirmación que confirma el activo intercambio entre estas colonias de la periferia austral del virreinato del Perú. ${ }^{109}$ Así, la influencia de Arauco en la economía de esta región abarcó, a través de inter-redes, a provincias tan alejadas como el Río de la Plata. Los recursos naturales de estas provincias encontraron en Chile un mercado alternativo al peruano y al circuito atlántico, aunque los historia-

109 Archivo General de la Nación, Sala IX, Libro Original, Actas del Extinto Cabildo de Buenos Aires, folio 68; y de Massiac, Barthélemy: Plan francés de conquista de Buenos Aires, 1660 1693. Buenos Aires, 1999, págs. 66-67; 106-107; y 122. 
dores se han concentrado en el comercio con el Alto Perú durante el siglo XVII. Las redes mercantiles que enlazaban Santiago con Mendoza, Córdoba y Buenos Aires, sin embargo, demuestran que el establecimiento del ejército en Arauco provocó cambios de larga duración, no solamente en Chile sino también en una amplia zona de la periferia austral del virreinato peruano. Esta influencia se verifica en el flujo comercial a través de redes mercantiles que demuestran que la medida militar que tomó la Corona después de Curalaba tuvo consecuencias que trascendieron ampliamente la coyuntura defensiva. La presencia del ejército con su situado, en efecto, aceleró la explotación de recursos a escala local y regional, impulsando el comercio a través de inter-redes por toda la periferia austral del imperio, y durante la totalidad del siglo XVII. 